\title{
Ascorbate-and Iron-Driven Redox Activity of Dp44mT and Emodin Facilitates Peroxidation
}

\section{of Micelles and Bicelles}

O.Yu. Selyutina, ${ }^{\text {a, }}$ P.A. Kononova, ${ }^{\text {a }}$ V.E. Koshman, ${ }^{\text {a }}$ E.A. Shelepova, ${ }^{\text {a }}$ M. Gholam Azad, ${ }^{\mathrm{b}}$ R. Afroz, ${ }^{\mathrm{b}}$ M. Dharmasivam, ${ }^{\mathrm{b}}$ P.V. Bernhardt, ${ }^{\mathrm{c}}$ N. E. Polyakov, ${ }^{\mathrm{a}, \mathrm{d}}$ and D.R. Richardson. ${ }^{\text {be }}$

${ }^{a}$ Institute of Chemical Kinetics and Combustion, Institutskaya St., 3, 630090, Novosibirsk, Russia; ${ }^{b}$ Centre for Cancer Cell Biology and Drug Discovery, Griffith Institute for Drug Discovery, Griffith University, Nathan, Brisbane, Queensland, 4111, Australia. Department of Chemistry, University of Queensland, St. Lucia, Brisbane, Queensland, 4072, Australia; ${ }^{d}$ Institute of Solid State Chemistry and Mechanochemistry, Kutateladze St., 18, 630128, Novosibirsk, Russia; and ${ }^{e}$ Department of Pathology and Biological Responses, Nagoya University Graduate School of Medicine, Nagoya 466-8550, Japan

*Corresponding authors: Dr. Olga Selyutina, Institute of Chemical Kinetics and Combustion, Institutskaya St., 3, 630090, Novosibirsk, Russia. Email: olga.gluschenko@gmail.com; Dr. Des R. Richardson, Centre for Cancer Cell Biology and Drug Discovery, Griffith Institute for Drug Discovery, Griffith University, Nathan, Brisbane, Queensland, 4111, Australia. Email: d.richardson@griffith.edu.au

\section{$\underline{\text { Abstract }}$}

Background: Iron (Fe)-induced oxidative stress leads to reactive oxygen species that damage biomembranes, with this mechanism being involved in the activity of some anti-cancer chemotherapeutics. Methods: Herein, we compared the effect of Fe complexes of the ligand, di-2pyridylketone 4,4-dimethyl-3-thiosemicarbazone (Dp44mT), or the potential ligand, Emodin, on lipid peroxidation in cell membrane models (micelles and bicelles). These studies were performed in 
the presence of hydrogen peroxide $\left(\mathrm{H}_{2} \mathrm{O}_{2}\right)$ and the absence or presence of ascorbate. Results: In the absence of ascorbate, $\mathrm{Fe}(\mathrm{II}) /$ Emodin mixtures incubated with $\mathrm{H}_{2} \mathrm{O}_{2}$ demonstrated slight pro-oxidant properties on micelles versus $\mathrm{Fe}(\mathrm{II})$ alone, while the $\mathrm{Fe}(\mathrm{III})-\mathrm{Dp} 44 \mathrm{mT}$ complex exhibited marked antioxidant properties. Examining more physiologically relevant phospholipid-containing bicelles, the $\mathrm{Fe}(\mathrm{II})$ - and $\mathrm{Fe}(\mathrm{III})-\mathrm{Dp} 44 \mathrm{mT}$ complexes demonstrated antioxidant activity without ascorbate. Upon adding ascorbate, there was a significant increase in the peroxidation of micelles and bicelles in the presence of unchelated $\mathrm{Fe}(\mathrm{II})$ and $\mathrm{H}_{2} \mathrm{O}_{2}$. The addition of ascorbate to $\mathrm{Fe}(\mathrm{III})-\mathrm{Dp} 44 \mathrm{mT}$ substantially increased the peroxidation of micelles and bicelles, with the Fe(III)-Dp44mT complex being reduced by ascorbate to the $\mathrm{Fe}(\mathrm{II})$ state, explaining the increased reactivity. Electron paramagnetic resonance spectroscopy demonstrated ascorbyl radical anion generation after mixing ascorbate and Emodin, with signal intensity being enhanced by $\mathrm{H}_{2} \mathrm{O}_{2}$. This finding suggested Emodin semiquinone radical formation that could play a role in its reactivity via ascorbate-driven redox cycling. Examining cultured melanoma cells in vitro, ascorbate at pharmacological levels enhanced the anti-proliferative activity of Dp44mT and Emodin. Conclusions and General Significance: Ascorbate-driven redox cycling of Dp44mT and Emodin promotes their antiproliferative activity.

\section{Introduction}

Iron (Fe)-induced generation of reactive oxygen species (ROS) can result in cell membrane peroxidation and is observed in Fe overload disease [1,2]. Lipid peroxidation leads to alterations in the packing of lipid bilayers $[3,4]$, which alters permeability and the phase transition temperature [4,5]. Oxidative stress can participate in oncogenesis and provoke tumor growth [6,7], but also can 
be implemented as part of the design of anti-cancer therapies [8,9]. The generation of ROS, such as superoxide radical $\left(\mathrm{O}_{2}{ }^{-}\right)$, peroxyl radical $\left(\mathrm{ROO}^{\bullet}\right)$, hydroxyl radical $(\mathrm{OH} \bullet)$, and hydrogen peroxide $\left(\mathrm{H}_{2} \mathrm{O}_{2}\right)$, can react with fatty acids, resulting in peroxidation [10]. The hydroxyl radical is one of the most reactive forms of oxygen and is generated by the Fenton and Haber-Weiss reactions in the presence of Fe ions $[11,12]$.

This study focused on the effect of several agents that possess anti-cancer activity, namely 6methyl-1,3,8-trihydroxyanthraquinone (Emodin; Fig. 1A) [13], and the thiosemicarbazone, di-2pyridylketone 4,4-dimethyl-3-thiosemicarbazone (Dp44mT; Fig. 1B) [14,15]. The effect of the potential Emodin-Fe complex (Fig. 1C) and well-known Dp44mT-Fe complex (Fig. 1D) was examined on Fe-catalyzed peroxidation reactions. These studies utilized two membrane models, namely micelles composed of linoleic acid (LA; Fig. 2A) and bicelles prepared from the phospholipids, 1,2-dilinoleoyl-sn-glycero-3-phosphocholine (DLPC; Fig. 2B) and 1,2-diheptanoylsn-glycero-3-phosphocholine (DHPC; Fig. 2C). The Fe-dependent peroxidation of LA is well characterized and involves the following stages [16-18]: (1) generation of ROS via the Fenton reaction; (2) initiation of the reaction with LA (abstraction of a hydrogen from position (*) in Fig. $\mathbf{2 A}$ with the formation of a lipid radical, $\mathrm{L} \cdot) ;(3)$ propagation with the formation of hydroperoxides, aldehydes, and epoxides; and (4) the termination stage (formation of polymers).

Equation

$$
\begin{aligned}
& \mathrm{Fe}^{2+}+\mathrm{H}_{2} \mathrm{O}_{2} \rightarrow \mathrm{Fe}^{3+}+\mathrm{OH}^{\cdot}+\mathrm{OH}^{-} \\
& \mathrm{LH}+\mathrm{OH} \cdot \rightarrow \mathrm{L} \cdot+\mathrm{H}_{2} \mathrm{O} \\
& \mathrm{L} \cdot+\mathrm{O}_{2} \rightarrow \mathrm{LOO} \cdot \\
& \mathrm{LOO} \cdot+\mathrm{LH} \rightarrow \mathrm{LOOH}+L \cdot \\
& \mathrm{LOOH} \rightarrow \mathrm{LO} \cdot \rightarrow \text { epoxides, hydroperoxides, aldehydes } \\
& L \cdot+\mathrm{L} \cdot \rightarrow \mathrm{L}-\mathrm{L} \\
& \mathrm{LOO} \cdot+\mathrm{L} \cdot \rightarrow \text { LOOL }
\end{aligned}
$$




$$
\mathrm{LOO}+\mathrm{LOO} \rightarrow \mathrm{LOOL}+\mathrm{O}_{2}
$$

The influence of ascorbate on this process is mediated by the reduction of $\mathrm{Fe}^{3+}$ to $\mathrm{Fe}^{2+}$ :

$$
\mathrm{AscH}+\mathrm{Fe}^{3+} \rightarrow \mathrm{Asc}^{\bullet^{-}}+\mathrm{Fe}^{2+}+\mathrm{H}^{+}
$$

The literature indicates that ascorbate exhibits pro-oxidant and antioxidant properties in terms of lipid peroxidation, depending on the conditions [19-21]. Ascorbate can also form mixed complexes with different ligands, which can be both redox-active and redox-inactive [22-26]. Further, the role of transition metals in the pro-oxidant activity of ascorbate and its role in ROS generation has been previously investigated in terms of anti-cancer therapy [21,27-31].

The chelation of Fe by ligands affects ROS generation and lipid peroxidation in liposomes and micelles [32-35]. Most studies report inhibition of lipid oxidation using various ligands [33-35], while some quinones increase ROS generation upon reaction with transition metal ions [36,37], resulting in lipid oxidation [34,38]. For example, the semiquinone radical can be formed upon reaction with NADH or thiols, leading to ROS [34,38]. A number of quinones, including Emodin, have been examined as anti-cancer agents, with one mechanism of action being DNA-binding $[39,40]$. Another potential mechanism of anti-tumor activity may be mediated through the ability of quinones to bind $\mathrm{Fe}$ and form redox active complexes that induce membrane peroxidation $[32,35]$. Emodin [41-44] and other hydroxyanthraquinones [45,46], including the anti-cancer drug, doxorubicin [45,47], may act as bidentate ligands, with doxorubicin affecting tumor cell Fe metabolism [47]. As quinones of this type are potentially bidentate, ligand to metal ratios of 1:1, 2:1, and 3:1 may be expected. The formula of the quinone complexes with divalent metal ions has been described as $\mathrm{M}(\mathrm{II})(\text { quinone })_{2}\left(\mathrm{H}_{2} \mathrm{O}\right)_{2}(\mathrm{M}(\mathrm{II})=\mathrm{Fe}, \mathrm{Mn}, \mathrm{Cr}, \mathrm{Co}$, Ni, etc.; Fig. 1C), while 3:1 ligand to metal ion ratios have been reported for the Fe(III) complexes [44-46]. However, evidence for the ligation of Fe by Emodin remains cursory and requires further investigation. 
The Fe(III)-quinone complex can be reduced through various reductants $[42,44-46]$, leading to ROS and the conversion of the quinone to semiquinone radicals $[45,46]$. During the Haber-Weiss and Fenton reactions, which are catalyzed by $\mathrm{Fe}$ and $\mathrm{H}_{2} \mathrm{O}_{2}$, highly reactive $\mathrm{OH} \cdot$ are produced $[45,46]$. Some quinone metal complexes decrease tumor cell proliferation and are more effective than the anti-cancer drug, cis-platin [42]. Emodin has been reported to possess both antioxidant [48-50] and pro-oxidant activity [51,52], although there are no data on the effect of Emodin on lipid peroxidation in the presence of ascorbate and Fe.

The thiosemicarbazone class of anti-cancer agents are also of interest due to their broad anti-tumor activity [53]. Traditionally, thiosemicarbazone anti-tumor activity was associated with inhibition of ribonucleotide reductase, but also more recently with the up-regulation of tumor and metastasis suppressor proteins and the inhibition of oncogenic signaling [54-58]. Additionally, there is a major role for oxidative stress in the anti-tumor activity of some thiosemicarbazone metal complexes, especially those of the di-2-pyridylketone thiosemicarbazone (DpT) class [14,59-61]. These agents include Dp44mT, which showed marked anti-tumor efficacy [14,62-64]. Notably, Dp44mT is a well-characterized tridentate ligand that can form 2:1 ligand to metal complexes with Fe [59] (Fig. 1D). Copper and Fe complexes of Dp44mT result in lysosomal membrane permeabilization induced by $\operatorname{ROS}[60,65,66]$. However, direct assessment of lipid peroxidation mediated via Dp44mT-Fe complexes and the effects of ascorbate on this process have never been examined.

The current investigation examines the reaction of Dp44mT and Emodin with Fe in the presence and absence of ascorbate on lipid peroxidation in two membrane model systems, namely micelles and bicelles. It was demonstrated that ascorbate reduces Fe(III)-Dp44mT to Fe(II)-Dp44mT that enhances lipid peroxidation. The generation of the ascorbyl radical anion $\left(\right.$ Asc $\left.^{-}\right)$was observed after mixing ascorbate and Emodin, with electron paramagnetic resonance (EPR) signal intensity being 
enhanced by $\mathrm{H}_{2} \mathrm{O}_{2}$. This finding suggested Emodin semiquinone radical formation that could play a role in its reactivity via ascorbate-driven redox cycling. The use of ascorbate to facilitate redox cycling of these potential anti-cancer agents is discussed as part of a strategy to facilitate their antitumor activity, which was demonstrated in vitro using cell culture.

\section{Materials and Methods}

\subsection{Ligands and Fe complexes}

The ligand, Dp44mT, was synthesized and characterized by elemental analysis, ESI-MS, ${ }^{1} \mathrm{H}$ NMR, and UV-Vis spectrophotometry, as described previously [59]. To prepare the 2:1 Dp44mT-Fe(III) complex, a hot ethanolic solution of Dp44mT (1 mM) was added slowly, with constant stirring, to a 
hot ethanolic solution of $\mathrm{Fe}\left(\mathrm{ClO}_{4}\right)_{3} \cdot \mathrm{H}_{2} \mathrm{O}(0.5 \mathrm{mM})$, and the resulting solution then refluxed for $1 \mathrm{~h}$ [59]. After cooling the reaction mixture to room temperature, the resulting solid product was collected by filtration, washed with diethyl ether, dried under vacuum, and recrystallized from methanol. The formation of the 2:1 Dp44mT Fe(III) complex was confirmed by elemental analysis, ESI-MS, and UV-Vis spectrophotometry and was in good agreement with that prepared previously [59]. The Fe(II)-Dp44mT complex was freshly prepared in PBS (pH 7.4) immediately prior to experiments by mixing a 2:1 molar ratio of Dp44mT $(0.2 \mathrm{mM})$ and $\mathrm{Fe}(\mathrm{II})$ as $\mathrm{FeSO}_{4}(0.1 \mathrm{mM})$.

Emodin was purchased from the Sigma-Aldrich Chemical Company (St. Louis, MO). A 2:1 Emodin/Fe mixture $(0.1 \mathrm{mM})$ was freshly prepared in PBS (pH 7.4) immediately prior to experiments by mixing a 2:1 molar ratio of Emodin $(0.2 \mathrm{mM})$ and $\mathrm{Fe}(\mathrm{II})$ as $\mathrm{FeSO}_{4}(0.1 \mathrm{mM})$.

\subsection{Preparation of bicelles}

Powdered components (lipids, ligands, ligand-metal complexes) were dissolved in chloroform, the solvent dried, and the resulting film hydrated. To accelerate the formation of bicelles, three freezethaw cycles were performed. The DLPC/DHPC ratio was 1:2, with the total lipid concentration being $12 \mathrm{mM}$.

\subsection{Sample preparation for lipid peroxidation studies}

Reaction mixtures for the ${ }^{1} \mathrm{H}$ NMR studies consisted of LA micelles (3.5 mM of LA; >99.0\% Purity; Shanghai Aladdin Bio-Chem Technology Co., Ltd, Shanghai, China) or bicelles constituted in a molar ratio of 1:2 of DLPC/DHPC (>99\% purity; Avanti Polar Lipids, Inc., Birmingham, AL). In reactions with hydrogen peroxide, $0.5 \mathrm{M} \mathrm{H}_{2} \mathrm{O}_{2}$ was added with $0.1 \mathrm{mM}$ of $\mathrm{FeSO}_{4}$ freshly prepared in PBS ( $\mathrm{pH}$ 7.4). For studies examining the effects of Emodin or Dp44mT on LA oxidation via the Fenton reaction (Equation (1)), these agents were added to the lipid solution in chloroform before drying and removal of the solvent and subsequent hydration in PBS (pH 7.4). 
The final Fe concentration of the potential complexes was $0.1 \mathrm{mM}$ (i.e., [Emodin or Dp44mT] $=0.2$ $\mathrm{mM}$ and $[\mathrm{Fe}]=0.1 \mathrm{mM}$ ) for direct comparison to the $\mathrm{FeSO}_{4}$ control.

To study the effect of the Fe(III)-Dp44mT complex or Fe(III)/Emodin mixtures on LA oxidation, these agents were added into a micelle or bicelle suspension in PBS ( $\mathrm{pH} 7.4)$ at a final concentration of $0.1 \mathrm{mM}$ (i.e., [Emodin or Dp44mT] $=0.2 \mathrm{mM}$ and $[\mathrm{Fe}]=0.1 \mathrm{mM}$ ). For studies examining the effect of ascorbate, a final concentration of $2.5 \mathrm{mM}$ was utilized. The ${ }^{1} \mathrm{H}$ NMR spectra were recorded on a Bruker AVHD-500 (500 MHz) NMR spectrometer (Bruker, Billerica, MA) using a temperature of $303 \mathrm{~K}$.

\subsection{UV-Vis spectrophotometry}

Emodin or Dp44mT $(0.1 \mathrm{mM})$ and $\mathrm{FeSO}_{4}(0.05 \mathrm{mM})$ were dissolved in PBS (pH 7.4) and stirred for $2 \mathrm{~h} / 20{ }^{\circ} \mathrm{C}$. For experiments with the Fe(III)-Dp44mT complex, ascorbate (0.01-0.8 mM) was added to the complex (0.05 mM) dissolved in PBS ( $\mathrm{pH} 7.4)$ and stirred for $2 \mathrm{~h} / 20{ }^{\circ} \mathrm{C}$. Measurements were done using an SF-2000 UV-Vis spectrophotometer (Spectrum, Moscow, Russia) using a $1 \mathrm{~cm}$ quartz cuvette.

\subsection{EPR studies}

Emodin $(10 \mathrm{mM})$ and ascorbate $(10 \mathrm{mM})$ were dissolved in a mixture of DMSO $(10 \% \mathrm{v} / \mathrm{v})$ and water, with $\mathrm{KOH}$ being added to achieve a $\mathrm{pH}$ of 9 to stabilize the semiquinone radical [67]. The final concentration of $\mathrm{H}_{2} \mathrm{O}_{2}$ added to the solution was $10 \mathrm{mM}$. The EPR spectra were recorded using a Spinscan X instrument (Linev Adani, Minsk, Belarus). The EPR parameters used were frequency: 9.4331 GHz, power: $10 \mathrm{~mW}$, modulation frequency: $100 \mathrm{kHz}$, and modulation amplitude: $1.00 \mathrm{G}$.

\subsection{Cyclic voltammetry}


Cyclic voltammograms of Emodin $(1 \mathrm{mM})$, Emodin $(1 \mathrm{mM})$ plus ammonium ferrous sulfate (1 $\mathrm{mM})$, and Emodin $(1 \mathrm{mM})$ plus ammonium ferric sulfate $(1 \mathrm{mM})$ were prepared in water: ethanol (2:1) containing $0.1 \mathrm{M} \mathrm{NaCl}$ and $50 \mathrm{mM}$ Bis-Tris buffer ( $\mathrm{pH}$ 7). Measurements were obtained using a BAS100B/W potentiostat equipped with an aqueous $\mathrm{Ag} / \mathrm{AgCl}$ reference electrode, a glassy carbon working electrode, and Pt wire auxiliary electrode.

\subsection{Relative lipophilicity $\left(\log P_{\text {calc }}\right)$}

The relative lipophilicity of Dp44mT and Emodin was calculated using the program ChemDraw Pro 12.0 (PerkinElmer, Waltham, MA) using Crippen's fragmentation procedure.

\subsection{Molecular dynamics simulations}

Molecular dynamics simulations were performed to understand the interactions of Dp44mT and Emodin with phospholipid-containing membranes using the Gromacs 2018.4 package and GROMOS54a7 force field. The topology of Dp44mT and Emodin was built using the Automated Topology Builder [68]. For lipid simulations, the 1,2-dioleoyl-sn-glycero-3-phosphocholine (DOPC; Fig. 2D) lipid model introduced by Poger was utilized [69]. The simple point charge (SPC) model of water molecules was implemented.

The simulation was performed in the NPT ensemble with constant pressure ( 1 bar) and constant temperature $\mathrm{T}=310 \mathrm{~K}$, which were maintained by the semi-isotropic Parrinello-Rahman barostat [70] and Nose-Hoover thermostat [71]. For these simulations, neutral agents at physiological pH (7.4) were utilized, as the charge of a compound plays a critical role in membrane permeation and its biological activity [60,72]. For electrostatic interactions, the PME method with the fourth-order of cubic interpolation and a grid of 0.16 was used [73]. The initial configuration of the system contained the bilayer consisting of 128 lipid molecules surrounded by water $(\sim 10,000$ water 
molecules) and a Dp44mT or Emodin molecule located in water outside the bilayer. For both systems with Dp44mT and Emodin, one production run of a 600 ns duration was performed.

\subsection{Biological Studies}

\subsubsection{Cell culture}

The human melanoma cell line, SK-MEL-28 $\left(\mathrm{ATCC}^{\circledR} \mathrm{HTB}^{\circledR}-72^{\mathrm{TM}}\right.$ ), was purchased from the American Type Culture Collection (ATCC®, Rockville, MD, USA). Cells were grown in minimum essential medium (MEM; Life Technologies, CA, USA) supplemented with $10 \%$ (v/v) fetal bovine serum (FBS; Sigma-Aldrich), 1\% (v/v) non-essential amino acids, 1\% (v/v) penicillin/streptomycin, $1 \%$ (v/v) sodium pyruvate (Sigma-Aldrich) and Fungizone (0.28 ng/mL; Gibco). Through standard procedures, the cells were grown at $37{ }^{\circ} \mathrm{C}$ under a $5 \% \mathrm{CO}_{2}$-humidified atmosphere in an incubator (Forma Scientific, Marietta, OH, USA) [74]. The authenticity of cells was assessed by viability, recovery, growth, morphology, cytogenetic analysis, antigen expression, DNA profile, and isoenzymology by the provider. The cells were routinely examined for mycoplasma contamination according to standard protocols [75].

\subsubsection{Cellular proliferation assay}

Both Dp44mT and Emodin were dissolved in DMSO to a stock concentration of $10 \mathrm{mM}$ and then diluted in culture media containing $10 \%$ FBS. For culture experiments, the maximum DMSO content in media did not exceed $0.5 \%(\mathrm{v} / \mathrm{v})$, and at this level, did not affect tumor cell proliferation. To determine the anti-proliferative activity of the Dp44mT and Emodin, the well-established 3-(4,5dimethylthiazol-2-yl)-2,5-diphenyltetrazolium bromide-(MTT)-based cell viability assay was implemented [76].

The SK-MEL-28 cells were seeded into 96-well microtiter plates at a density of $1.5 \times 10^{4}$ cells/well and allowed to adhere overnight. The Dp44mT $(0-25 \mu \mathrm{M})$ and Emodin $(0-100 \mu \mathrm{M})$ were either added alone or with ascorbate $(50 \mu \mathrm{M}$ or $1 \mathrm{mM})$ and incubated with the cells for $72 \mathrm{~h} / 37{ }^{\circ} \mathrm{C}$. After 
this incubation, $20 \mu \mathrm{L}$ of MTT ( $5 \mathrm{mg} / \mathrm{mL})$ was added to each well and the plates incubated for a further $2 \mathrm{~h} / 37^{\circ} \mathrm{C}$. Then $100 \mu \mathrm{L}$ of DMSO was added, and the absorbance of the formazan product was measured at $570 \mathrm{~nm}$. The formazan product formation was directly proportional to the viability of the cells measured by Trypan blue staining [76]. The half-maximal inhibitory concentration $\left(\mathrm{IC}_{50}\right)$ was defined as the concentration of the agent that reduced formazan absorbance by half, which equals $50 \%$ cellular viability [76].

\subsection{Statistical analysis}

Statistical analyses were performed using GraphPad Prism (GraphPad Software, San Diego). For comparison of two experimental conditions, a two-tailed, unpaired Student's $t$-test was performed using at least 3 independent experiments. Statistical significance was set at $p<0.05$. Data are presented as mean \pm standard deviation (number of experiments).

\section{Results and Discussion}

3.1 Fe-mediated peroxidation of LA micelles in the presence of $\mathrm{H}_{2} \mathrm{O}_{2}$ 
Micelles are widely used to mimic the chemical behavior of biological membranes and to study lipid reactivity [77]. LA was selected for initial studies with $\mathrm{Fe}$ and $\mathrm{H}_{2} \mathrm{O}_{2}$, as it is an example of a polyunsaturated fatty acid where its peroxidation is well described [77,78]. Studies examining the peroxidation of LA $(3.5 \mathrm{mM})$ were performed in the presence of $\mathrm{H}_{2} \mathrm{O}_{2}(0.5 \mathrm{M})$ and $\mathrm{FeSO}_{4}(0.1 \mathrm{mM})$ at $20{ }^{\circ} \mathrm{C}(\mathrm{pH} 7.4)$. In these studies, $\mathrm{H}_{2} \mathrm{O}_{2}$ was used in excess $(0.5 \mathrm{M})$ to ensure reproducible results, as it decomposes spontaneously to oxygen and water. The $\mathrm{H}_{2} \mathrm{O}_{2}$ is used in this experimental model as an oxidant to study the effect of ascorbate, Fe, Emodin, and Dp44mT on lipid peroxidation.

The results in Figure 3A demonstrate the initial ${ }^{1} \mathrm{H}$ NMR spectrum of LA in the reaction mixture at pH 7.4 and the spectra after a 2-, 4-, or 24-h incubation at $20{ }^{\circ} \mathrm{C}$ of LA with $\mathrm{H}_{2} \mathrm{O}_{2}$ and $\mathrm{FeSO}_{4}$ (see Materials and Methods). The signal at $2.7 \mathrm{ppm}$ corresponds to bis-allylic protons of LA (asterisk in Fig. 2A), and the initiation stage of LA oxidation is the abstraction of a hydrogen atom at this position leading to a decrease in its intensity as a function of time (Fig. 3A). This decrease is accompanied by the formation of conjugated dienes and L· (see Equation (2)) [16]. After bis-allylic hydrogen abstraction, $\mathrm{L} \cdot$ are generated with the formation of new conjugated double bonds, which results in the complete disappearance of the bis-allylic proton in the structure of the products [1618]. As such, the ${ }^{1} \mathrm{H}$ NMR signal at 2.7 ppm (Fig. 3A) should completely disappear if no initial LA remains in solution. The decrease in the intensity of the ${ }^{1} \mathrm{H}$ NMR signal at $0.8 \mathrm{ppm}$ (Fig. 3A) corresponds to methyl protons and may disappear due to the formation of polymeric products (see Equation (4)). These polymeric products probably have restricted motion due to their size and are invisible in solution ${ }^{1} \mathrm{H}$ NMR spectra. The increase of signal intensity at $1.6 \mathrm{ppm}$ (Fig. 3A) could be caused by the formation of oxygen addition products, such as 9,10-12,13-diepoxyoctadecanoate. However, this signal is difficult to analyze due to line broadening and the overlap with other signals. Similar results under analogous conditions were also obtained examining DLPC in bicelles with abstraction of its bis-allylic protons being demonstrated (see Section 3.2 below; Fig. 3B). 
Control experiments using the mixture of LA $+\mathrm{Fe}(\mathrm{II})$ in the absence of $\mathrm{H}_{2} \mathrm{O}_{2}$ demonstrated no decrease in the intensity of LA signals in the spectrum for $24 \mathrm{~h} / 20^{\circ} \mathrm{C}$. To study the kinetics of LA peroxidation, experiments then examined the decay of the intensity of this ${ }^{1} \mathrm{H}$ NMR signal to characterize the rate of initiation in the presence and absence of the Fe mixed with Dp44mT or Emodin and ascorbate (Fig. 4). This methodology has previously been implemented to estimate the antioxidant activity of the complexes of other ligands [79].

The kinetics of LA $(3.5 \mathrm{mM})$ peroxidation at $\mathrm{pH} 7.4$ in the reaction with $\mathrm{H}_{2} \mathrm{O}_{2}(0.5 \mathrm{M}) / 20{ }^{\circ} \mathrm{C}$ were measured for $\mathrm{Fe}(\mathrm{II})$ (as $\mathrm{FeSO}_{4} ; 0.1 \mathrm{mM}$ ), and Dp44mT or Emodin at $0.2 \mathrm{mM}$, in the absence (Fig. 4A) or presence (Fig. 4B) of ascorbate $(2.5 \mathrm{mM})$. The experimental points were approximated by an exponential decay, and the observed first-order reaction rate constant derived from fitting the parameters using the Levenberg-Marquardt algorithm via Origin 2017 software (Northampton, MA). The calculated reaction rate constants are given in Table $\mathbf{1 .}$

While the $\mathrm{Fe}(\mathrm{II})-\mathrm{Dp} 44 \mathrm{mT}$ and $\mathrm{Fe}(\mathrm{II}) /$ Emodin mixtures were freshly prepared with $\mathrm{Fe}(\mathrm{II})$ (as $\mathrm{FeSO}_{4}$ ), no attempt was made to prevent facile oxidation to the $\mathrm{Fe}(\mathrm{III})$ state, which is well known to occur due to the presence of oxygen in solution. As such, it can be expected that a considerable proportion of these complexes could be in the $\mathrm{Fe}(\mathrm{III})$ state, and this is critical to consider regarding the interpretation of the results below, particularly upon the addition of ascorbate.

In the absence of Emodin or Dp44mT, the observed oxidation of LA was consistent with Equations (1-4). Taking into account that the reaction proceeds in an excess of $\mathrm{H}_{2} \mathrm{O}_{2}$, the fast conversion of $\mathrm{Fe}(\mathrm{II})$ to $\mathrm{Fe}(\mathrm{III})$ occurs within a millisecond time scale in the first stage due to the reaction in Equation (1). The rate constant of this reaction is $63 \mathrm{M}^{-1} \mathrm{~s}^{-1}[80,81]$. We assume that the limiting stage of LA oxidation is the conversion of Fe(III) to Fe(II) according to the reaction in Equation (6) below, which proceeds with a rate constant of $0.0027 \mathrm{M}^{-1} \mathrm{~s}^{-1}[80,81]$. 


$$
\mathrm{Fe}^{3+}+\mathrm{H}_{2} \mathrm{O}_{2} \rightarrow \mathrm{Fe}^{2+}+\mathrm{OOH} \cdot+\mathrm{H}^{+}
$$

\subsubsection{LA micelle peroxidation in the absence of ascorbate}

In the absence of ascorbate, Fe(II)-Dp44mT resulted in a rate constant of LA peroxidation, which was 7.6-fold greater $(p<0.005)$ than Fe(III)-Dp44mT (Table 1). The low reactivity of the Fe(III)Dp44mT complex in LA peroxidation in the absence of ascorbate was clearly evident relative to the other experimental conditions examined (Fig. 4A). In this case, a marked and significant $(p<$ 0.005) 10.9-fold decrease of the rate constant was demonstrated relative to the unchelated $\mathrm{Fe}(\mathrm{II})$ control, indicating its antioxidant effects (Table 1). In the absence of ascorbate, the Fe(II)/Emodin mixture exhibited slight pro-oxidant properties, demonstrating the greatest rate constant of LA peroxidation, which was 1.5 -fold greater than the control (i.e., $\mathrm{Fe}(\mathrm{II})$ alone), 2.2-fold greater than Fe(II)-Dp44mT, and 16.7-fold greater than Fe(III)-Dp44mT (Table 1).

\subsubsection{LA micelle peroxidation in the presence of ascorbate}

The addition of ascorbate and unchelated $\mathrm{Fe}(\mathrm{II})\left(\right.$ as $\left.\mathrm{FeSO}_{4}\right)$ to LA significantly $(p<0.005)$ increased the rate constant of LA peroxidation by 7.5 -fold versus the analogous condition in the absence of ascorbate (Table 1; Fig. 4A, B). This observation is probably due to the fast transformation of $\mathrm{Fe}(\mathrm{III})$ to $\mathrm{Fe}(\mathrm{II})$ in the presence of ascorbate, as per the reaction in Equation (5). Comparing the rate constants for $\mathrm{Fe}(\mathrm{III})-\mathrm{Dp} 44 \mathrm{mT}$ and $\mathrm{Fe}(\mathrm{II})-\mathrm{Dp} 44 \mathrm{mT}$, upon the addition of ascorbate, there was a significant $(p<0.005) 3.9$-fold increase in the rate constant for $\mathrm{Fe}(\mathrm{III})$ Dp44mT and significant $(p<0.005)$ 2.2-fold increase for the Fe(II)-Dp44mT complex relative to when it was examined without ascorbate (Table 1). The addition of ascorbate to the $\mathrm{Fe}(\mathrm{II}) / \mathrm{Emodin}$ mixture also resulted in a significant $(p<0.005)$ 2.2-fold increase of the rate constant of LA peroxidation relative to $\mathrm{Fe}(\mathrm{II}) /$ Emodin mixture in the absence of ascorbate (Table 1; Fig. 4A). 
In the presence of ascorbate, Fe, and Dp44mT or Emodin, the rate constants of LA peroxidation were significantly $(p<0.005)$ less than that of the Fe(II) only control (Table 1; Fig. 4B). This observation demonstrates that $\mathrm{Fe}(\mathrm{II})$ reacts more readily to induce LA peroxidation in the absence of Dp44mT or Emodin.

In summary, the studies in Fig. 4 and Table $\mathbf{1}$ indicate that in the absence of ascorbate, the $\mathrm{Fe}(\mathrm{II}) /$ Emodin mixture acts as a pro-oxidant to slightly increase LA peroxidation versus the $\mathrm{Fe}(\mathrm{II})$ control. In contrast, the $\mathrm{Fe}(\mathrm{III})-\mathrm{Dp} 44 \mathrm{mT}$ complex does not effectively induce LA peroxidation without ascorbate and acts as an antioxidant relative to the $\mathrm{Fe}(\mathrm{II})$ control. In the presence of ascorbate, all the Fe complexes became significantly $(p<0.005)$ more active in terms of the rate of LA peroxidation. This latter effect may indicate the formation of pro-oxidant species in the presence of ascorbate, that is, the potential reduction of Fe(III)-Dp44mT to Fe(II)-Dp44mT and the possible formation of the Emodin semiquinone radical. These hypotheses are examined in additional studies described below.

\subsection{Peroxidation of lipid bicelles}

Apart from the micelles examined above (Figs. 3A and 4; Table 1), lipid bicelles are another cell membrane model widely used in solution ${ }^{1} \mathrm{H}$ NMR studies [82]. In contrast to micelles, bicelles have a bilayer structure, which more closely corresponds to the physiological organization of the cell membrane, but they are still relatively small in size, which allows analysis by solution ${ }^{1} \mathrm{H}$ NMR [82]. In the current investigation, bicelles were prepared in PBS (pH 7.4) using DLPC/DHPC in a ratio of 1:2 (see Materials and Methods). In this model, only DLPC with its bis-allylic protons (see asterisks; Fig. 2B) takes part in the reaction initiation stage because DHPC does not have this moiety (Fig. 2C). The results in Figure 3B demonstrate the initial ${ }^{1} \mathrm{H}$ NMR spectrum of the DLPC/DHPC mixture and the spectra after a 2- and 24-h incubation at $20{ }^{\circ} \mathrm{C}(\mathrm{pH} 7.4)$ with $\mathrm{H}_{2} \mathrm{O}_{2}$ $(0.5 \mathrm{mM})$ and $\mathrm{FeSO}_{4}(0.1 \mathrm{mM}$; see Materials and Methods for details). As found for LA in Fig. 3A, 
the signal at 2.7 ppm corresponds to bis-allylic protons of DLPC (asterisk in Fig. 2B), and the initiation stage of oxidation is the abstraction of a hydrogen atom at this position leading to a decrease in signal intensity as a function of time (Fig. 3B).

Kinetics of lipid peroxidation in bicelles at $20{ }^{\circ} \mathrm{C}$ in the presence of $\mathrm{H}_{2} \mathrm{O}_{2}$ was examined by ${ }^{1} \mathrm{H}$ NMR in the absence and presence of ascorbate $(2.5 \mathrm{mM}), \mathrm{Fe}(\mathrm{II})\left(\right.$ as $\left.\mathrm{FeSO}_{4} ; 0.1 \mathrm{mM}\right)$, or the $\mathrm{Fe}$ mixtures with Dp44mT or Emodin at $0.1 \mathrm{mM}$ (i.e., [Emodin or Dp44mT] $=0.2 \mathrm{mM}$ and $[\mathrm{Fe}]=0.1$ $\mathrm{mM}$; Figure 5A, B). The reaction rate constants from these studies are given in Table 2.

In the absence of Dp44mT or Emodin, the rate constants under control conditions (i.e., in the presence of unchelated $\mathrm{Fe}(\mathrm{II})$ alone) for the peroxidation rates of lipids in bicelles (Table 2) were very similar $(p>0.05)$ to that of LA micelles (Table 1), with and without ascorbate. However, the effect of Dp44mT and Emodin on the oxidation of DLPC/DHPC bicelles (Table 2) was in some regards different from that observed for LA micelles (Table 1).

With Fe(II)/Emodin mixtures, the peroxidation activity was similar in bicelles and micelles in the absence of ascorbate to slightly accelerate peroxidation relative to the Fe(II) control (Tables 1 and 2). However, upon the addition of ascorbate to Fe(II) and Emodin, no significant increase in the peroxidation rate constant occurred in bicelles (cf. $5.20 \pm 0.70 \times 10^{-4} \mathrm{~s}^{-1}$ vs. $5.30 \pm 0.70 \times 10^{-4} \mathrm{~s}^{-1}$; Table 2). This observation was in contrast to the marked increase in the rate constant observed in micelles after adding ascorbate with Fe(II) and Emodin $\left(c f .5 .50 \pm 0.30 \times 10^{-4} \mathrm{~s}^{-1}\right.$ vs. $11.90 \pm 0.40 \mathrm{x}$ $10^{-4} \mathrm{~s}^{-1}$; Table 1).

As observed for micelles in the absence of ascorbate, Fe(III)-Dp44mT acted as an antioxidant to inhibit the peroxidation rate constant in bicelles versus the unchelated Fe(II) control (viz., from 4.10 x $10^{-4} \mathrm{~s}^{-1}$ to $0.02 \times 10^{-4} \mathrm{~s}^{-1}$; Table 2). However, in contrast to micelles where Fe(II)-Dp44mT had 
little effect on peroxidation relative to the unchelated Fe(II) control in the absence of ascorbate

(Table 1), Fe(II)-Dp44mT acted as an antioxidant and resulted in a significant $(p<0.005)$ decrease in the rate constant of bicelle peroxidation $\left(0.30 \times 10^{-4} \mathrm{~s}^{-1}\right)$ relative to unchelated Fe(II) $\left(4.10 \times 10^{-4}\right.$ $\mathrm{s}^{-1}$; Table 2).

Upon the addition of ascorbate, the rate constant for the peroxidation of bicelles was significantly ( $p$ $<0.001$ ) increased 43- and 550-fold for Fe(II)-Dp44mT and Fe(III)-Dp44mT, respectively (Table

2). This finding is probably explained through the rapid conversion of $\mathrm{Fe}(\mathrm{III})$ to $\mathrm{Fe}$ (II) in the Dp44mT complex via the reducing activity of ascorbate. To dissect the mechanisms involved, UVVis spectrophotometry was implemented in the studies below with Dp44mT (Fig. 6), while both UV-Vis spectrophotometry and EPR were used for examining the activity of Emodin (Figs. 7 and 8).

\subsection{UV-Vis Spectrophotometry demonstrates that ascorbate can reduce Fe(III)-Dp44mT to the Fe(II)-Dp44mT complex}

To examine the effect of ascorbate on the Fe complex of Dp44mT, UV-Vis spectrophotometry was performed using a mixture of $\mathrm{FeSO}_{4}(0.05 \mathrm{mM}), \mathrm{Dp} 44 \mathrm{mT}(0.1 \mathrm{mM})$, and ascorbate $(0-0.8 \mathrm{mM})$ in PBS at $\mathrm{pH} 7.4 / 20^{\circ} \mathrm{C}$ (Fig. 6). Upon the addition of increasing concentrations of ascorbate, a minor $\mathrm{Fe}(\mathrm{II})-\mathrm{Dp} 44 \mathrm{mT}$ peak at $\sim 620-660 \mathrm{~nm}$ was observed even in the presence of $0.1 \mathrm{mM}$ of ascorbate, with higher concentrations $(0.2-0.8 \mathrm{mM})$ increasing the intensity of the Fe(II)-Dp44mT peak (Fig. 6). The same peak at $\sim 620-660 \mathrm{~nm}$ also appeared in the presence of ascorbate if the Fe(III)-Dp44mT complex was used instead of the mixture of $\mathrm{FeSO}_{4}$ and Dp44mT (data not shown).

Previous studies from our laboratories have demonstrated that the peak at $\sim 620-660 \mathrm{~nm}$ (Fig. 6) corresponds to the metal-to-ligand charge transfer band of the Fe(II)-Dp44mT complex, leading to a distinctive green solution $[59,83]$. In contrast, ascorbate has a single absorption peak at $250 \mathrm{~nm}$, 
while the Fe(III)-Dp44mT complex does not have an absorption peak in the 500-700 nm region, with the solution appearing brown in color $[59,83]$. Hence, the increased intensity of the peak at 620-660 nm upon the addition of ascorbate (Fig. 6) is consistent with the conversion of Fe(III)Dp44mT to the Fe(II)-Dp44mT complex. The peak at $\sim 620-660 \mathrm{~nm}$ was not observed in the absorption spectrum of the Fe(II) and Dp44mT solution before the addition of ascorbate (Fig. 6). This finding suggests oxidation of the Fe(II)-Dp44mT complex to the Fe(III) state by oxygen before ascorbate was added. Considering these observations, the following reaction can be suggested [83]:

$\left[F e^{I I}(D p 44 m T)_{2}\right]+O_{2}{ }^{k_{o x}}\left[F e^{I I I}(D p 44 m T)_{2}\right]^{+}+O_{2}^{-\cdot}$

These results demonstrate that in oxygen-containing solutions of Fe(II) + Dp44mT, that the Fe(III)Dp44mT complex is dominant, while upon the addition of ascorbate, the following reaction occurs:

$A s c H^{-}+\left[F e^{I I I}(D p 44 m T)_{2}\right]^{+} \stackrel{-H+}{-} A s c^{\bullet-}+\left[F e^{I I}(D p 44 m T)_{2}\right]$

The studies and deductions from Fig. 6 could explain the significant increase in the peroxidation rate constant of the Fe(III)-Dp44mT complex in the micelles and bicelles upon the addition of ascorbate (Tables 1 and 2). The mechanism of the redox reaction of Fe(II)- and Fe(III)-Dp44mT complexes with ascorbate can be described by Scheme 1.

\section{Scheme 1.}




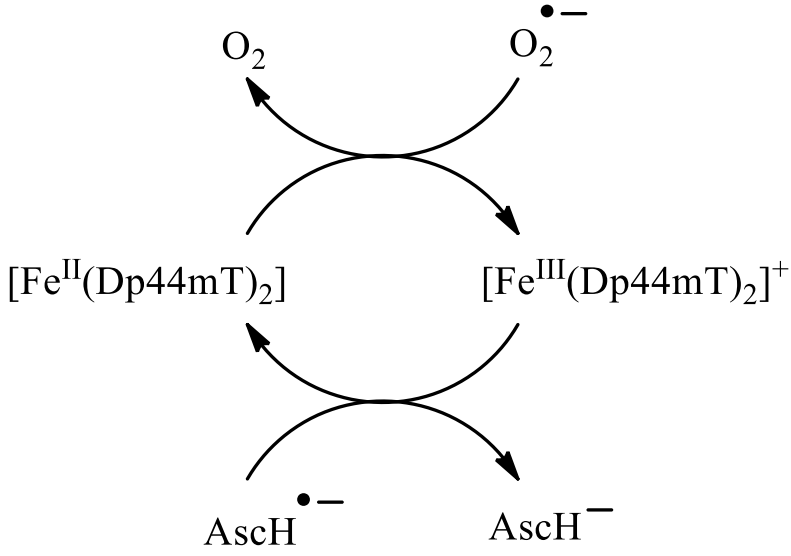

Studies at $\mathrm{pH} 7.4 / 20{ }^{\circ} \mathrm{C}$ also examined the effect of adding $0.2 \mathrm{mM}$ ascorbate to $\mathrm{Dp} 44 \mathrm{mT}(0.1 \mathrm{mM})$ in the absence of $\mathrm{FeSO}_{4}$ (Suppl. Fig. 1). This addition of ascorbate led to a marked increase in the absorbance at $265 \mathrm{~nm}$, which is the reported absorption maximum for ascorbate [84] However, no alteration in this initial spectrum was demonstrated after an incubation of $1 \mathrm{~h} / 20{ }^{\circ} \mathrm{C}$ (Suppl. Fig. S1).

Collectively, these studies in Figure 6 and Supplemental Figure 1 demonstrated that the effect of ascorbate was specific for the Fe complex rather than the ligand and was due to the ability of ascorbate to reduce $\left[\mathrm{Fe}^{(\mathrm{III})}(\mathrm{Dp} 44 \mathrm{mT})_{2}\right]^{+}$to $\left[\mathrm{Fe}^{(\mathrm{III})}(\mathrm{Dp} 44 \mathrm{mT})_{2}\right]$.

\subsection{Addition of ascorbate leads to a marked decrease in the UV-Vis spectral intensity of Emodin, with EPR spectroscopy indicating ascorbyl radical anion formation.}

To further dissect the mechanism of the interaction between ascorbate and Emodin, UV-Vis spectrophotometry (Fig. 7) and EPR spectrometry (Fig. 8) were performed. These studies demonstrated a marked decrease in spectral intensity of Emodin as a function of time upon the addition of ascorbate and in the absence of $\mathrm{Fe}(\mathrm{II})$ at $20{ }^{\circ} \mathrm{C}$ (Fig. 7A). A similar decrease in the spectral intensity was also observed for the Emodin and ascorbate mixture in the presence of Fe(II) (Fig. 7B). 
Considering this observation, it was hypothesized that Emodin/Fe mixture may directly react with ascorbate, with the following reactions occurring (Equation (9)), where $Q$ is the quinone, Emodin, and $Q H \bullet$ is the Emodin semiquinone radical [85]:

$Q+A s c H^{-} \rightarrow Q H^{\bullet}+A s C^{\bullet-}$,

It has been reported for quinones whose cytotoxic activity was potentiated by ascorbate that these agents had reduction potentials of -480 to $-680 \mathrm{mV}[86,87]$. The reduction potential of Emodin has been reported to be $-0.658 \mathrm{~V}$ versus $\mathrm{SCE}$ (i.e., $-418 \mathrm{mV}$ versus the $\mathrm{NHE}$ ) at $\mathrm{pH} 7.2[88,89]$, and as such, this reaction may occur depending on the $\mathrm{pH}$. This hypothesis was then examined by EPR spectroscopy using a mixture of Emodin $(10 \mathrm{mM})$, ascorbate $(10 \mathrm{mM})$, and $\mathrm{H}_{2} \mathrm{O}_{2}(10 \mathrm{mM}$; Fig. 8), with the spectra being recorded under alkaline conditions $(\mathrm{pH} 9)$ to stabilize the semiquinone radical [67]. The signal of the ascorbyl radical anion $\left(\mathrm{Asc}^{\bullet^{-}}\right)$doublet with proton hyperfine coupling of $1.8 \mathrm{G}$ [25] was observed after adding Emodin, with the addition of $\mathrm{H}_{2} \mathrm{O}_{2}$ leading to an increase in the Asc $^{-}$signal intensity (Fig. 8). Considering these results, the following reactions (Equations (10) and (11)) with Emodin can be suggested, where $\mathrm{QH}_{2}$ is the Emodin hydroquinone [87]:

$$
\begin{aligned}
& Q \mathrm{H} \bullet+\mathrm{H}_{2} \mathrm{O}_{2} \rightarrow \mathrm{QH}_{2}+\mathrm{HO}_{2} \bullet \\
& \mathrm{AscH}^{-}+\mathrm{HO}_{2} \bullet \rightarrow \mathrm{AsC}^{\bullet-}+\mathrm{H}_{2} \mathrm{O}_{2}
\end{aligned}
$$

In LA peroxidation studies, it was observed that ascorbate substantially increased the peroxidation rate in the system containing Fe(II) and Emodin relative to the absence of ascorbate (Table 1). This could be explained by the known mechanisms of ROS generation via the interaction of quinones with electron donors in the presence of $\mathrm{Fe}[32,37,87,90]$. However, studies using cyclic 
voltammetry demonstrated no significant changes in the electrochemistry of Emodin upon the addition of either $\mathrm{Fe}(\mathrm{II})$ or $\mathrm{Fe}(\mathrm{III})$, and the small decrease in current observed was due to dilution effects (Supplementary Fig. 2A). The 2-electron reduction of Emodin to its anthraquinol form occurs at essentially the same potential as that determined previously and described above $[88,89]$. Furthermore, the characteristic UV-Vis absorption maximum of Emodin (425 nm; Supplementary Fig. 2B) was retained upon addition of a $c a$. 10-fold excess of either $\mathrm{Fe}(\mathrm{II})$ or $\mathrm{Fe}(\mathrm{III})$ at $\mathrm{pH} 7$. Collectively, while Emodin has the potential to act as a bidentate ligand (Fig. 1C), these electrochemistry and spectrophotometry studies suggest it does not effectively chelate Fe under these conditions. Therefore, throughout this article we refer to Emodin/Fe mixtures rather than the Emodin-Fe complex. Other redox reactions not involving Fe chelation by Emodin must be occurring to explain the enhanced LA peroxidation observed with the Emodin/Fe mixture and ascorbate relative to that without ascorbate (Table 1). These reactions may involve Emodin semiquinone radical formation that could play a role in its reactivity via ascorbate-driven redox cycling

In contrast to the effect of the Fe(II) and Emodin on LA micelle peroxidation (Table 1), the addition of ascorbate did not stimulate the peroxidation of the bicelles by $\mathrm{Fe}(\mathrm{II}) / \mathrm{Emodin}$ relative to that observed in the absence of ascorbate (Table 2). This finding may suggest differences in the redox interactions of the $\mathrm{Fe}(\mathrm{II}) /$ Emodin system and ascorbate with bicelles relative to micelles. In fact, for Emodin, significant differences were observed for its ${ }^{1} \mathrm{H}$ NMR spectra in LA micelles versus DLPC/DHPC bicelles, which suggests dissimilar interactions (Fig. 9A). The absence of the Emodin signal in LA micelles could be caused by significant line broadening due to the lower mobility of Emodin in the micelle relative to the DLPC/DHPC bicelle. In contrast, for Dp44mT, such pronounced changes in its ${ }^{1} \mathrm{H}$ NMR spectrum were not observed comparing bicelles with LA micelles, with the ${ }^{1} \mathrm{H}$ NMR signals being detectable in both membrane models (Fig. 9B). 


\subsection{Interaction of Emodin and Dp44mT with the lipid bilayer}

As alluded to above, differences in how ascorbate induces lipid peroxidation in the presence of Fe and Emodin mixtures and Fe-Dp44mT complexes could be related to their interactions with membranes. Many factors dictate the interaction of drugs with the cell membrane, including lipophilicity, size, solubility, charge, etc. [91]. Lipophilicity and charge are key aspects of pharmacopoeia that determine their biological activity [72,76], as discussed for agents of the DpT class, such as Dp44mT [14], and also Emodin [91]. The relative lipophilicity of Dp44mT and Emodin was important to compare ( $\log P_{\text {calc }}=2.19[92,93]$ and 1.74 , respectively), and considering that Dp44mT permeates membranes and binds intracellular Fe pools [14], it can be suggested that Emodin's lipophilicity is compatible with membrane permeability. This deduction is supported by biological studies where Emodin was reported to affect multiple cellular and molecular processes [94,95], suggesting its ability to permeate membranes and gain intracellular access.

In terms of charge, both Emodin (Fig. 1A) and Dp44mT (Fig. 1B) 2are polyprotic compounds, and thus, all studies below were examined at physiological $\mathrm{pH}(\mathrm{pH}$ 7.4) where the agents are neutral [60,96], which favors membrane permeability. To further understand the interaction of Emodin and Dp44mT with lipids, molecular dynamics simulations were performed using the 1,2-dioleoyl-snglycero-3-phosphocholine (DOPC; Fig. 2D) lipid model [69]. DOPC is a phosphatidylcholine (36:2), which is generally the most abundant phospholipid in animal cell membranes, and thus, provides a physiologically relevant model for the simulation. Molecular dynamics simulations were utilized to assess the interaction of Dp44mT and Emodin with membranes, as they have been extensively implemented to predict drug behavior and activity [91,97,98]. Unfortunately, these types of simulations do not effectively accommodate relatively heavy atoms such as iron, and thus, Dp44mT-Fe complex or potential Emodin-Fe complexes could not be effectively studied using this methodology. The purpose of these simulations was to understand the structural features of Dp44mT and Emodin that lead to interactions with the 
phospholipid membrane that could aid understanding of how these agents react with Fe to induce peroxidation.

In these simulations, when placed into the water outside the bilayer, Dp44mT and Emodin could interact with this membrane (Fig. 10A-D). The Dp44mT molecule quickly descended (in the first $10 \mathrm{~ns}$ ) into the membrane surface (Fig. 10A), where it was mainly located during the length of the simulation (600 ns). Dp44mT could penetrate the hydrophobic part of the bilayer (Fig. 10B), move into the surrounding water, and return to the bilayer surface (Fig. 10A). As Dp44mT is highly permeable to tumor cells, these simulation data were in good agreement with the observed ability of this agent to penetrate tumor cell membranes, bind intracellular Fe pools, and then be effluxed out of cells [14,62-64].

It was also apparent that the electronegative thiocarbonyl sulfur atom of Dp44mT (Fig. 1B) interacted with the positively charged nitrogen atoms of the polar heads of DOPC during almost all the simulation. This fact can be deduced first from the intense first peak of the radial distribution function of the $\mathrm{S}$ atom of Dp44mT and the $\mathrm{N}$ atom of DOPC (Fig. 11A). In molecular dynamics simulations, the radial distribution function defines the probability of finding a particle at distance $r$ from another tagged particle [99]. In Fig. 11A, the X-axis is the distance (" $r$ " in $n m$ ) between the $S$ atom of Dp44mT and the $\mathrm{N}$ atom of the phospholipid, with the Y-axis being "density" (g(r)). Thus, the maximum of $\mathrm{g}(\mathrm{r})$ is the most probable distance between the Dp44mT S atom and the lipid $\mathrm{N}$ atom, which is approximately $0.4 \mathrm{~nm}$ (Fig. 11A). Second, the sustained interaction of the phospholipid $\mathrm{N}$ atom and the $\mathrm{S}$ atom of $\mathrm{Dp} 44 \mathrm{mT}$ is also demonstrated from the graph of the minimum distance between the Dp44mT S atom and the $\mathrm{N}$ atom of DOPC as a function of time during the simulation (Fig. 11B). 
As shown in Fig. 11B, the minimal distance between the Dp44mT S atom and the lipid $\mathrm{N}$ atom is about $0.4 \mathrm{~nm}$ for most of the duration of the simulation, that is, between $\sim 10-$ and 600 -ns. The thiocarbonyl $\mathrm{S}$ atom of $\mathrm{Dp} 44 \mathrm{mT}$ is one of the three ligating sites that becomes unavailable for interactions after complexation with Fe (Fig. 1D). This finding may explain the low peroxidation activity of the Fe(II)-Dp44mT complex in DLPC/DHPC bicelles relative to LA micelles (Tables 1 and 2).

As observed for Dp44mT (Fig. 10A), Emodin quickly descended (in the first $~ 10$ ns) into the membrane surface (Fig. 10C), where it was mainly located and did not penetrate the hydrophobic region during the simulation. However, when Emodin was placed in the membrane hydrophobic region, it remained in this area during the simulation with some contact with the membrane surface (Fig. 10D). This observation could suggest that Emodin becomes trapped to some extent within the lipid membrane, which may accentuate its peroxidation activity.

It was also observed that the hydroxyl-groups of Emodin (namely, $\mathrm{OH} 1, \mathrm{OH} 2$, and $\mathrm{OH} 4$; Fig. 12) interact with the phosphate group of the DOPC, probably via hydrogen bonding (H-bonding), during almost all the simulation. This conclusion can be deduced from the first peak of the radial distribution function of the interaction between the Emodin hydroxyl moieties and the phosphate group of DOPC (Fig. 12). In Figure 12, $\mathrm{OH}$ 1, $\mathrm{OH} 2$, and $\mathrm{OH} 4$ are the closest groups to the phosphate moiety of the lipid, with the most probable distance between these hydroxyl moieties and the phosphate group being $\sim 0.5 \mathrm{~nm}$. Notably, $\mathrm{OH} 1$ and $\mathrm{OH} 4$ may potentially be involved in $\mathrm{Fe}$ chelation along with carbonyl 5, leading to their sequestration within the complex and inhibiting their interactions with the lipid (Fig. 1B). As such, we hypothesize that if an Emodin-Fe complex forms, it may associate with the lipid bilayer via $\mathrm{H}$-bond formation between $\mathrm{OH} 2$ (which remains free if $\mathrm{Fe}$ complexation occurs) and the phosphate group of the phospholipid to facilitate peroxidation. As described previously in relation to Supplemental Figure 2, evidence for the 
formation of an Emodin-Fe complex under the current conditions was not obtained, despite its potential bidentate ligating mode (Fig. 2C).

Differences in peroxidation activity were noted for Emodin and Dp44mT in the phospholipid bicelle model relative to micelles. In fact, a significant effect of ascorbate at increasing LA peroxidation by $\mathrm{Fe}(\mathrm{II}) /$ Emodin mixture in micelles was observed (Table 1), while no effect of ascorbate was demonstrated for Fe(II)/Emodin mixture in bicelles (Table 2). This difference can be speculated to relate to the interaction of the Emodin hydroxyl group (i.e., $\mathrm{OH} 2$; Fig. 12) with phospholipid containing bicelles, but not in LA-containing micelles, which do not contain phospholipid (Fig. 2A). Considering this, significant differences were observed for the ${ }^{1} \mathrm{H}$ NMR spectra of Emodin in LA micelles versus DLPC/DHPC bicelles (Fig. 9A), which suggests different interactions and lower mobility in the LA micelle, which could lead to different peroxidation kinetics.

\subsection{Biological studies: Combination of Dp44mT and Emodin with ascorbate enhances their anti-proliferative activity against melanoma cells}

Considering the studies above suggesting the potential of ascorbate to stimulate redox chemistry of the mixtures of Fe and Dp44mT or Emodin, it can be hypothesized that this may lead to the increased generation of cytotoxic ROS that could lead to greater anti-proliferative activity. To examine the ability of the Dp44mT and Emodin to inhibit cellular proliferation in the absence or presence of ascorbate, studies were performed examining human SK-MEL-28 melanoma cells using incubations of $72 \mathrm{~h}$. This cell-type was chosen for these studies as its response to Dp44mT and other agents has been well characterized in our laboratory [14]. We compared the effects of adding physiological levels of ascorbate at $50 \mu \mathrm{M}$, which are observed in human blood, relative to pharmacological levels of $1000 \mu \mathrm{M}$, which can only be achieved after intravenous administration [21] (Fig. 13) 
Examining Dp44mT demonstrated that the combination with ascorbate at $1000 \mu \mathrm{M}$ resulted in significant $(p<0.001-0.05)$ increase in its anti-proliferative activity relative to Dp44mT alone at Dp44mT concentrations from 3.125-25 $\mu \mathrm{M}$ (Fig. 13A). Combination of Dp44mT with ascorbate at $50 \mu \mathrm{M}$ led to a less consistent increase in anti-proliferative activity which was only significantly $(p$ $<0.01-0.05)$ different relative to Dp44mT alone at concentrations from 3.125-12.5 $\mu \mathrm{M}$ (Fig. 13A). Regarding Emodin, again the most consistent increase in anti-proliferative activity was observed upon combination with ascorbate at $1000 \mu \mathrm{M}$, where a significant $(p<0.001-0.05)$ increase in antiproliferative activity was observed relative to Emodin at concentrations from 1.562-100 $\mu \mathrm{M}$ (Fig. 13B). Ascorbate alone at both 50 and $1000 \mu \mathrm{M}$ had no significant effect on the proliferation of SKMel-28 cells (Fig. 13C).

Collectively, these studies demonstrate that the combination of ascorbate at $1000 \mu \mathrm{M}$ with Dp44mT or Emodin increased their anti-proliferative activity against SK-Mel-28 melanoma cells.

\section{Summary and Conclusions}

In summary, the current investigation has examined the effect of the Fe in the presence of Emodin, and the thiosemicarbazone, Dp44mT, on Fe-induced lipid peroxidation in two membrane models using ${ }^{1} \mathrm{H}$ NMR, UV-Vis, and EPR spectroscopies. The Fe(II)/Emodin mixture acted as a mild prooxidant to slightly increase peroxidation in LA micelles relative to $\mathrm{Fe}(\mathrm{II})$ alone in the absence of ascorbate, with this pro-oxidant activity being negligible in bicelles. In contrast, the Fe(III)Dp44mT complex acted as an antioxidant to inhibit peroxidation versus that observed with free $\mathrm{Fe}(\mathrm{II})$ in the absence of ascorbate in micelles and bicelles. Upon adding ascorbate, the rate of peroxidation in both micelles and bicelles increased most robustly for $\mathrm{Fe}(\mathrm{III})-\mathrm{Dp} 44 \mathrm{mT}$, although this rate was far less than that observed with free Fe(II). As such, in the presence of ascorbate, Emodin and Dp44mT acted as antioxidants in both membrane models relative to free Fe(II). 
Furthermore, it was demonstrated that the addition of ascorbate resulted in the reduction of Fe(III) to $\mathrm{Fe}(\mathrm{II})$ in the Dp44mT complex, explaining its increased ability to induce lipid peroxidation (Fig. 14).

The present results allow us to conclude that ascorbate has a significant effect on the mechanisms of anti- and pro-oxidant activity of Dp44mT or Emodin and should be considered in studying the mechanisms of their activity and their potential applications in treatment. Studies in vitro demonstrated the effective potentiation of anti-proliferative activity against melanoma cells of Emodin or Dp44mT with ascorbate at $1000 \mu \mathrm{M}$, suggesting further studies in vivo with these combinations are warranted. Such effects have been studied in terms of so-called "catalytic therapy of cancer" that is based on ROS generation where a transition metal complex acts as a catalyst [86]. This therapeutic strategy is based on the relative sensitivity of tumors to redox stress, with an inverse correlation being reported between antioxidant enzyme levels and the histological grade of the cancer [86]. Most often, agents for catalytic therapy are ascorbate and complexes of phthalocyanine or porphyrins with transition metals [100-102].

While ascorbate-driven quinone redox cycling has been described [86], there are no studies assessing this using the DpT class of thiosemicarbazones, such as Dp44mT. For these latter agents, redox cycling of their transition metal complexes plays a crucial role in its ability to induce lysosomal membrane permeabilization via ROS-induced damage [14,60,96]. This activity leads to potent and selective anti-cancer efficacy and the ability to overcome P-glycoprotein-mediated resistance [103]. The current study demonstrates for the first time the direct ability of the $\mathrm{Fe}(\mathrm{II})$ complexes of Dp44mT to induce membrane lipid peroxidation, which is potently enhanced by ascorbate (Fig. 14), suggesting a potential combination strategy. In fact, this combination strategy was validated by in vitro studies using melanoma cells (Fig. 13). Considering Emodin, it is of interest that previous studies [52] and the current investigation demonstrated that ascorbate 
enhanced its anti-proliferative activity against cancer cells [52], with this paper clarifying the mechanisms involved. That is, Emodin semiquinone radical formation that could play a role in its reactivity via ascorbate-driven redox cycling (Fig. 14).

\section{Supplementary Materials}

The following information are available in the Supplementary Materials: Suppl. Fig. 1: UV-Vis absorption spectra of Dp44mT and ascorbate in PBS (pH 7.4); Suppl. Fig. 2A: Cyclic voltammograms of Emodin in the presence and absence of Fe(II) and Fe(III); Suppl. Fig. 2B: UVVis absorption spectra of Emodin in the presence and absence of $\mathrm{Fe}(\mathrm{II})$ and $\mathrm{Fe}(\mathrm{III})$.

\section{Conflicts of Interest}

The authors declare no conflict of interest.

\section{Acknowledgments}

The reported study was funded by Russian Foundation for Basic Research (grant № 20-33-70019) and by the Russian Science Foundation (grant № 21-73-10037). E. A. Shelepova and N. E. Polyakov acknowledge core funding from the Russian Federal Ministry of Science and Higher Education. D.R. Richardson kindly thanks the National Health and Medical Research Council of Australia (NHMRC) for a Career Award, namely a Senior Principal Research Fellowship (APP1159596). 


\section{References}

[1] D.R. Richardson, P. Ponka, The molecular mechanisms of the metabolism and transport of iron in normal and neoplastic cells, Biochim. Biophys. Acta. 1331 (1997) 1-40. https://doi.org/10.1016/S0304-4157(96)00014-7.

[2] D.R. Richardson, R.T. Dean, Does free extracellular iron exist in haemochromatosis and other pathologies, and is it redox active?, Clin. Sci. 100 (2001) 237-238. https://doi.org/10.1042/cs1000237.

[3] P. Jurkiewicz, A. Olżyńska, L. Cwiklik, E. Conte, P. Jungwirth, F.M. Megli, M. Hof, Biophysics of lipid bilayers containing oxidatively modified phospholipids: insights from fluorescence and EPR experiments and from MD simulations, Biochim. Biophys. Acta. 1818 (2012) 2388-2402. https://doi.org/10.1016/j.bbamem.2012.05.020.

[4] J. Wong-ekkabut, Z. Xu, W. Triampo, I.-M. Tang, D.P. Tieleman, L. Monticelli, Effect of lipid peroxidation on the properties of lipid bilayers: A Molecular dynamics study, Biophys. J. 93 (2007) 4225-4236. https://doi.org/10.1529/biophysj.107.112565.

[5] J. Van der Paal, E.C. Neyts, C.C.W. Verlackt, A. Bogaerts, Effect of lipid peroxidation on membrane permeability of cancer and normal cells subjected to oxidative stress, Chem. Sci. 7 (2016) 489-498. https://doi.org/10.1039/c5sc02311d.

[6] B. Perillo, M. Di Donato, A. Pezone, E. Di Zazzo, P. Giovannelli, G. Galasso, G. Castoria, A. Migliaccio, ROS in cancer therapy: the bright side of the moon, Exp. Mol. Med. 52 (2020) 192-203. https://doi.org/10.1038/s12276-020-0384-2. 
[7] J.D. Hayes, A.T. Dinkova-Kostova, K.D. Tew, Oxidative stress in cancer, Cancer Cell. 38 (2020) 167-197. https://doi.org/10.1016/j.ccell.2020.06.001.

[8] D.S. Kalinowski, D.R. Richardson, Future of toxicology of iron chelators and differing modes of action and toxicity: the changing face of iron chelation therapy, Chem. Res. Toxicol. 20 (2007) 715-720. https://doi.org/10.1021/tx700039c.

[9] T.P. Wijesinghe, M. Dharmasivam, C.C. Dai, D.R. Richardson, Innovative therapies for neuroblastoma: The surprisingly potent role of iron chelation in up-regulating metastasis and tumor suppressors and down-regulating the key oncogene, N-myc, Pharmacol. Res. 173 (2021) 105889. https://doi.org/10.1016/j.phrs.2021.105889.

[10] G. Barrera, Oxidative stress and lipid peroxidation products in cancer progression and therapy, ISRN Oncol. 2012 (2012). https://doi.org/10.5402/2012/137289.

[11] T.A. Dix, J. Aikens, Mechanisms and biological relevance of lipid peroxidation initiation, Chem. Res. Toxicol. 6 (1993) 2-18. https://doi.org/10.1021/tx00031a001.

[12] Z. Cheng, Y. Li, What is responsible for the initiating chemistry of iron-mediated lipid peroxidation: an update, Chem. Rev. 107 (2007) 748-766. https://doi.org/10.1021/cr040077w.

[13] H.S. Tuli, V. Aggarwal, M. Tuorkey, D. Aggarwal, N.C. Parashar, M. Varol, R. Savla, G. Kaur, S. Mittal, K. Sak, Emodin: A metabolite that exhibits anti-neoplastic activities by modulating multiple oncogenic targets, Toxicol. In Vitro. 73 (2021) 105142. https://doi.org/10.1016/j.tiv.2021.105142.

[14] J. Yuan, D.B. Lovejoy, D.R. Richardson, Novel di-2-pyridyl-derived iron chelators with marked and selective anti-tumor activity: in vitro and in vivo assessment, Blood. 104 (2004) 1450-1458. https://doi.org/10.1182/blood-2004-03-0868.

[15] D.R. Richardson, D.S. Kalinowski, S. Lau, P.J. Jansson, D.B. Lovejoy, Cancer cell iron metabolism and the development of potent iron chelators as anti-tumour agents, Biochim. Biophys. Acta. 1790 (2009) 702-717. https://doi.org/10.1016/j.bbagen.2008.04.003.

[16] C. Schneider, An update on products and mechanisms of lipid peroxidation, Mol. Nutr. Food Res. 53 (2009) 315-321. https://doi.org/10.1002/mnfr.200800131.

[17] G. Spiteller, Linoleic acid peroxidation - the dominant lipid peroxidation process in low density lipoprotein — and its relationship to chronic diseases, Chem. Phys. Lipids. 95 (1998) 105-162. https://doi.org/10.1016/S0009-3084(98)00091-7.

[18] M.G. Cotticelli, A.M. Crabbe, R.B. Wilson, M.S. Shchepinov, Insights into the role of oxidative stress in the pathology of Friedreich ataxia using peroxidation resistant polyunsaturated fatty acids, Redox Biol. $1 \quad$ (2013) 398-404. https://doi.org/10.1016/j.redox.2013.06.004. 
[19] G.R. Buettner, B.A. Jurkiewicz, Catalytic metals, ascorbate and free radicals: combinations to avoid, Radiat. Res. 145 (1996) 532-541.

[20] J. Du, J.J. Cullen, G.R. Buettner, Ascorbic acid: Chemistry, biology and the treatment of $\begin{array}{lllll}\text { cancer, } & \text { Biochim. } & \text { Biophys. } & \text { Acta. } & 1826\end{array}$ https://doi.org/10.1016/j.bbcan.2012.06.003.

[21] D.-H. Bae, M. Gholam Azad, D.S. Kalinowski, D.J.R. Lane, P.J. Jansson, D.R. Richardson, Ascorbate and tumor cell iron metabolism: the evolving story and its link to pathology, Antioxid. Redox Signal. 33 (2020) 816-838. https://doi.org/10.1089/ars.2019.7903.

[22] F.I. Adam, P.L. Bounds, R. Kissner, W.H. Koppenol, Redox properties and activity of ironcitrate complexes: evidence for redox cycling, Chem. Res. Toxicol. 28 (2015) 604-614. https://doi.org/10.1021/tx500377b.

[23] M. Merkofer, R. Kissner, R.C. Hider, W.H. Koppenol, Redox properties of the iron complexes of orally active iron chelators CP20, CP502, CP509, and ICL670, Helv. Chim. Acta. 87 (2004) 3021-3034. https://doi.org/10.1002/hlca.200490272.

[24] L. Grillet, L. Ouerdane, P. Flis, M.T.T. Hoang, M.-P. Isaure, R. Lobinski, C. Curie, S. Mari, Ascorbate efflux as a new strategy for iron reduction and transport in plants, J. Biol. Chem. 289 (2014) 2515-2525. https://doi.org/10.1074/jbc.M113.514828.

[25] V.A. Timoshnikov, T.V. Kobzeva, N.E. Polyakov, G.J. Kontoghiorghes, Redox interactions of vitamin $\mathrm{C}$ and iron: inhibition of the pro-oxidant activity by deferiprone, Int. J. Mol. Sci. 21 (2020) 3967. https://doi.org/10.3390/ijms21113967.

[26] G.J. Kontoghiorghes, A. Kolnagou, C.N. Kontoghiorghe, L. Mourouzidis, V.A. Timoshnikov, N.E. Polyakov, Trying to solve the puzzle of the interaction of ascorbic acid and iron: redox, chelation and therapeutic implications, Medicines. $7 \quad$ (2020) 45. https://doi.org/10.3390/medicines7080045.

[27] J. Tian, D.M. Peehl, S.J. Knox, Metalloporphyrin synergizes with ascorbic acid to inhibit cancer cell growth through fenton chemistry, Cancer Biother. Radiopharm. 25 (2010) 439448. https://doi.org/10.1089/cbr.2009.0756.

[28] W. Zhong, T. Yan, M.M. Webber, T.D. Oberley, Alteration of cellular phenotype and responses to oxidative stress by manganese superoxide dismutase and a superoxide dismutase mimic in RWPE-2 human prostate adenocarcinoma cells, Antioxid. Redox Signal. 6 (2004) 513-522. https://doi.org/10.1089/152308604773934279.

[29] P.R. Gardner, D.D. Nguyen, C.W. White, Superoxide scavenging by Mn(II/III) tetrakis (1methyl-4-pyridyl) porphyrin in mammalian cells, Arch. Biochem. Biophys. 325 (1996) 20-28. https://doi.org/10.1006/abbi.1996.0003. 
[30] I. Batinic-Haberle, Z. Rajic, A. Tovmasyan, J.S. Reboucas, X. Ye, K.W. Leong, M.W. Dewhirst, Z. Vujaskovic, L. Benov, I. Spasojevic, Diverse functions of cationic Mn(III) Nsubstituted pyridylporphyrins, recognized as SOD mimics, Free Radic. Biol. Med. 51 (2011) 1035-1053. https://doi.org/10.1016/j.freeradbiomed.2011.04.046.

[31] X. Ye, D. Fels, A. Tovmasyan, K.M. Aird, C. Dedeugd, J.L. Allensworth, I. Kos, W. Park, I. Spasojevic, G.R. Devi, M.W. Dewhirst, K.W. Leong, I. Batinic-Haberle, Cytotoxic effects of $\mathrm{Mn}(\mathrm{III}) \mathrm{N}$-alkylpyridylporphyrins in the presence of cellular reductant, ascorbate, Free Radic. Res. 45 (2011) 1289-1306. https://doi.org/10.3109/10715762.2011.616199.

[32] S. Dikalov, P. Alov, D. Rangelova, Role of iron ion chelation by quinones in their reduction, OH-radical generation, and lipid peroxidation, Biochem. Biophys. Res. Commun. 195 (1993) 113-119. https://doi.org/10.1006/bbrc.1993.2017.

[33] P. Menasché, H. Antebi, L.-G. Alcindor, E. Teiger, G. Perez, Y. Giudicelli, R. Nordmann, A. Piwnica, Iron chelation by deferoxamine inhibits lipid peroxidation during cardiopulmonary bypass in humans., Circulation. 82 (1990) IV390-6.

[34] Y. Yoshida, S. Furuta, E. Niki, Effects of metal chelating agents on the oxidation of lipids induced by copper and iron, Biochim. Biophys. Acta. 1210 (1993) 81-88. https://doi.org/10.1016/0005-2760(93)90052-B.

[35] A.E. Alegría, G. Santiago, Structural and hydrophilicity requirements in quinone-induced lipid peroxidation of phosphatidylcholine vesicles, Toxicol. Environ. Chem. 65 (1998) 185-202. https://doi.org/10.1080/02772249809358568.

[36] I.D. Markova, N.E. Polyakov, O.Y. Selyutina, L.G. Fedenok, K.Y. Fedotov, I.A. Slepneva, T.V. Leshina, A.G. Pokrovsky, N.V. Vasilieva, L.M. Weiner, Light-stimulated generation of free radicals by quinones-chelators, Z. Phys. Chem. 231 (2017). https://doi.org/10.1515/zpch2016-0831.

[37] N. Polyakov, T. Leshina, L. Fedenok, I. Slepneva, I. Kirilyuk, J. Furso, M. Olchawa, T. Sarna, M. Elas, I. Bilkis, L. Weiner, Redox-active quinone chelators: properties, mechanisms of action, cell delivery, and cell toxicity, Antioxid. Redox Signal. 28 (2018) 1394-1403. https://doi.org/10.1089/ars.2017.7406.

[38] G. Powis, Free radical formation by anti-tumor quinones, Free Radic. Biol. Med. 6 (1989) 63101. https://doi.org/10.1016/0891-5849(89)90162-7.

[39] Y.-Y. Chen, S.-Y. Chiang, J.-G. Lin, J.-S. Yang, Y.-S. Ma, C.-L. Liao, T.-Y. Lai, N.-Y. Tang, J.-G. Chung, Emodin, aloe-emodin and rhein induced DNA damage and inhibited DNA repair gene expression in SCC-4 human tongue cancer cells, Anticancer Res. 30 (2010) 945-951. 
[40] M.B. Gholivand, S. Kashanian, H. Peyman, H. Roshanfekr, DNA-binding study of anthraquinone derivatives using Chemometrics methods, Eur. J. Med. Chem. 46 (2011) 26302638. https://doi.org/10.1016/j.ejmech.2011.03.034.

[41] L. Yang, J. Tan, B.-C. Wang, L.-C. Zhu, Synthesis, characterization, and anti-cancer activity of emodin-Mn(II) metal complex, Chin. J. Nat. Med. 12 (2014) 937-942. https://doi.org/10.1016/S1875-5364(14)60137-0.

[42] J. Tan, B. Wang, L. Yang, L. Zhu, Emodin transition metal complex with anti-tumor activity, preparation method of emodin transition metal complex and application of emodin transition metal complex, CN104058946A, 2014. https://patents.google.com/patent/CN104058946A/en (accessed October 14, 2021).

[43] B. Mandal, S. Singha, S.K. Dey, S. Mazumdar, S. Kumar, P. Karmakar, S. Das, Cu(II) complex of Emodin with improved anti-cancer activity as demonstrated by its performance on HeLa and Hep G2 cells - RSC Advances (RSC Publishing), RSC Adv. 66 (2017) 4140341418.

[44] V.Ya. Fain, B.E. Zaitsev, M.A. Ryabov, Metal complexes with 1,5- and 1,8-dihydroxy-9,10anthraquinones: electronic absorption spectra and structure of ligands, Russ. J. Coord. Chem. 30 (2004) 360-364. https://doi.org/10.1023/B:RUCO.0000026007.04814.ad.

[45] A. Jabłońska-Trypuć, G. Świderski, R. Krętowski, W. Lewandowski, Newly synthesized doxorubicin complexes with selected metals-synthesis, structure and anti-breast cancer activity, Mol. Basel Switz. 22 (2017). https://doi.org/10.3390/molecules22071106.

[46] H. Beraldo, A. Garnier-Suillerot, L. Tosi, F. Lavelle, Iron(III)-adriamycin and Iron(III)daunorubicin complexes: physicochemical characteristics, interaction with DNA, and antitumor activity, Biochemistry. 24 (1985) 284-289. https://doi.org/10.1021/bi00323a007.

[47] X. Xu, R. Sutak, D.R. Richardson, Iron chelation by clinically relevant anthracyclines: alteration in expression of iron-regulated genes and atypical changes in intracellular iron distribution and trafficking, Mol. Pharmacol. $73 \quad$ (2008) 833-844. https://doi.org/10.1124/mol.107.041335.

[48] X. Zhao, L. Lu, Y. Qi, M. Li, L. Zhou, Emodin extends lifespan of Caenorhabditis elegans through insulin/IGF-1 signaling pathway depending on DAF-16 and SIR-2.1, Biosci. Biotechnol. Biochem. 81 (2017) 1908-1916. https://doi.org/10.1080/09168451.2017.1365592.

[49] G. Srinivas, S. Babykutty, P.P. Sathiadevan, P. Srinivas, Molecular mechanism of emodin action: Transition from laxative ingredient to an anti-tumor agent, Med. Res. Rev. 27 (2007) 591-608. https://doi.org/10.1002/med.20095. 
[50] F. Vargas, Y. Díaz, K. Carbonell, Antioxidant and scavenging activity of Emodin, aloeemodin, and rhein on free-radical and reactive oxygen species, Pharm. Biol. 42 (2004) 342 348. https://doi.org/10.1080/13880200490519613.

[51] Y. Cui, B. Liu, J. Xie, P. Xu, H.-M. Habte-Tsion, Y. Zhang, The effect of Emodin on cytotoxicity, apoptosis and antioxidant capacity in the hepatic cells of grass carp (Ctenopharyngodon idellus), Fish Shellfish Immunol. $38 \quad$ (2014) 74-79. https://doi.org/10.1016/j.fsi.2014.02.018.

[52] S. Masaldan, V.V. Iyer, Exploration of effects of Emodin in selected cancer cell lines: enhanced growth inhibition by ascorbic acid and regulation of LRP1 and AR under hypoxialike conditions, J. Appl. Toxicol. 34 (2014) 95-104. https://doi.org/10.1002/jat.2838.

[53] Y. Yu, D.S. Kalinowski, Z. Kovacevic, A.R. Siafakas, P.J. Jansson, C. Stefani, D.B. Lovejoy, P.C. Sharpe, P.V. Bernhardt, D.R. Richardson, Thiosemicarbazones from the old to new: iron chelators that are more than just ribonucleotide reductase inhibitors, J. Med. Chem. 52 (2009) 5271-5294. https://doi.org/10.1021/jm900552r.

[54] N.T.V. Le, D.R. Richardson, Iron chelators with high anti-proliferative activity up-regulate the expression of a growth inhibitory and metastasis suppressor gene: a link between iron metabolism and proliferation, Blood. 104 (2004) 2967-2975. https://doi.org/10.1182/blood2004-05-1866.

[55] Z. Kovacevic, S. Chikhani, G.Y.L. Lui, S. Sivagurunathan, D.R. Richardson, The ironregulated metastasis suppressor NDRG1 targets NEDD4L, PTEN, and SMAD4 and inhibits the PI3K and Ras signaling pathways, Antioxid. Redox Signal. 18 (2013) 874-887. https://doi.org/10.1089/ars.2011.4273.

[56] S.V. Menezes, Z. Kovacevic, D.R. Richardson, The metastasis suppressor NDRG1 downregulates the epidermal growth factor receptor via a lysosomal mechanism by up-regulating mitogen-inducible gene 6, J. Biol. Chem. 294 (2019) 4045-4064. https://doi.org/10.1074/jbc.RA118.006279.

[57] B. Geleta, K.C. Park, P.J. Jansson, S. Sahni, S. Maleki, Z. Xu, T. Murakami, M. Pajic, M.V. Apte, D.R. Richardson, Z. Kovacevic, Breaking the cycle: Targeting of NDRG1 to inhibit bidirectional oncogenic cross-talk between pancreatic cancer and stroma, FASEB J. 35 (2021) e21347. https://doi.org/10.1096/fj.202002279R.

[58] J. Chekmarev, G.M. Azad, D.R. Richardson, The oncogenic signaling disruptor, NDRG1: molecular and cellular mechanisms of activity, Cells. $10 \quad$ (2021) 2382. https://doi.org/10.3390/cells10092382.

[59] D.R. Richardson, P.C. Sharpe, D.B. Lovejoy, D. Senaratne, D.S. Kalinowski, M. Islam, P.V. Bernhardt, Dipyridyl thiosemicarbazone chelators with potent and selective anti-tumor activity 
form iron complexes with redox activity, J. Med. Chem. 49 (2006) 6510-6521. https://doi.org/10.1021/jm0606342.

[60] D.B. Lovejoy, P.J. Jansson, U.T. Brunk, J. Wong, P. Ponka, D.R. Richardson, Anti-tumor activity of metal-chelating compound Dp44mT is mediated by formation of a redox-active copper complex that accumulates in lysosomes, Cancer Res. 71 (2011) 5871-5880. https://doi.org/10.1158/0008-5472.CAN-11-1218.

[61] D.R. Richardson, D.S. Kalinowski, V. Richardson, P.C. Sharpe, D.B. Lovejoy, M. Islam, P.V. Bernhardt, 2-Acetylpyridine thiosemicarbazones are potent iron chelators and antiproliferative agents: redox activity, iron complexation and characterization of their anti-tumor activity, J. Med. Chem. 52 (2009) 1459-1470. https://doi.org/10.1021/jm801585u.

[62] M. Whitnall, J. Howard, P. Ponka, D.R. Richardson, A class of iron chelators with a wide spectrum of potent anti-tumor activity that overcomes resistance to chemotherapeutics, Proc. Natl. Acad. Sci. U. S. A. 103 (2006) 14901-14906. https://doi.org/10.1073/pnas.0604979103.

[63] Z. Kovacevic, S. Chikhani, D.B. Lovejoy, D.R. Richardson, Novel thiosemicarbazone iron chelators induce up-regulation and phosphorylation of the metastasis suppressor N-myc downstream regulated gene 1: a new strategy for the treatment of pancreatic cancer, Mol. Pharmacol. 80 (2011) 598-609. https://doi.org/10.1124/mol.111.073627.

[64] Y. Yu, Y. Suryo Rahmanto, D.R. Richardson, Bp44mT: an orally active iron chelator of the thiosemicarbazone class with potent anti-tumour efficacy, Br. J. Pharmacol. 165 (2012) 148166. https://doi.org/10.1111/j.1476-5381.2011.01526.x.

[65] A.E. Stacy, D. Palanimuthu, P.V. Bernhardt, D.S. Kalinowski, P.J. Jansson, D.R. Richardson, Structure-activity relationships of di-2-pyridylketone, 2-benzoylpyridine, and 2-acetylpyridine thiosemicarbazones for overcoming Pgp-mediated drug resistance, J. Med. Chem. 59 (2016) 8601-8620. https://doi.org/10.1021/acs.jmedchem.6b01050.

[66] A.E. Stacy, D. Palanimuthu, P.V. Bernhardt, D.S. Kalinowski, P.J. Jansson, D.R. Richardson, Zinc(II)-thiosemicarbazone complexes are localized to the lysosomal compartment where they transmetallate with copper ions to induce cytotoxicity, J. Med. Chem. 59 (2016) 4965-4984. https://doi.org/10.1021/acs.jmedchem.6b00238.

[67] M. Sato-Watanabe, S. Itoh, T. Mogi, K. Matsuura, H. Miyoshi, Y. Anraku, Stabilization of a semiquinone radical at the high-affinity quinone-binding site $(\mathrm{QH})$ of the Escherichia coli botype ubiquinol oxidase, FEBS Lett. 374 (1995) 265-269. https://doi.org/10.1016/00145793(95)01125-x.

[68] M. Stroet, B. Caron, K.M. Visscher, D.P. Geerke, A.K. Malde, A.E. Mark, Automated topology builder version 3.0: prediction of solvation free enthalpies in water and hexane, J. Chem. Theory Comput. 14 (2018) 5834-5845. https://doi.org/10.1021/acs.jctc.8b00768. 
[69] D. Poger, W.F.V. Gunsteren, A.E. Mark, A new force field for simulating phosphatidylcholine bilayers, J. Comput. Chem. 31 (2010) 1117-1125. https://doi.org/10.1002/jcc.21396.

[70] M. Parrinello, A. Rahman, Polymorphic transitions in single crystals: A new molecular dynamics method, J. Appl. Phys. 52 (1981) 7182-7190. https://doi.org/10.1063/1.328693.

[71] W.G. Hoover, Canonical dynamics: Equilibrium phase-space distributions, Phys. Rev. A. 31 (1985) 1695-1697. https://doi.org/10.1103/PhysRevA.31.1695.

[72] D.R. Richardson, L.M. Wis Vitolo, G.T. Hefter, P.M. May, B.W. Clare, J. Webb, P. Wilairat, Iron chelators of the pyridoxal isonicotinoyl hydrazone class Part I. Ionisation characteristics of the ligands and their relevance to biological properties, Inorganica Chim. Acta. 170 (1990) 165-170. https://doi.org/10.1016/S0020-1693(00)80471-5.

[73] U. Essmann, L. Perera, M.L. Berkowitz, T. Darden, H. Lee, L.G. Pedersen, A smooth particle mesh Ewald method, J. Chem. Phys. 103 (1995) 8577-8593. https://doi.org/10.1063/1.470117.

[74] D.R. Richardson, E. Baker, The uptake of iron and transferrin by the human malignant melanoma cell, Biochim. Biophys. Acta. 1053 (1990) 1-12. https://doi.org/10.1016/01674889(90)90018-9.

[75] C.C. Uphoff, H.G. Drexler, Comparative PCR analysis for detection of mycoplasma infections in continuous cell lines, In Vitro Cell. Dev. Biol. Anim. 38 (2002) 79-85. https://doi.org/10.1290/1071-2690(2002)038<0079:CPAFDO>2.0.CO;2.

[76] D.R. Richardson, E.H. Tran, P. Ponka, The potential of iron chelators of the pyridoxal isonicotinoyl hydrazone class as effective anti-proliferative agents, Blood. 86 (1995) 42954306. https://doi.org/10.1182/blood.V86.11.4295.bloodjournal86114295.

[77] B. Mihaljević, I. Tartaro, C. Ferreri, C. Chatgilialoglu, Linoleic acid peroxidation vs. isomerization: a biomimetic model of free radical reactivity in the presence of thiols, Org. Biomol. Chem. 9 (2011) 3541-3548. https://doi.org/10.1039/C1OB05083D.

[78] M. Laguerre, M. Tenon, A. Bily, S. Birtić, Toward a spatiotemporal model of oxidation in lipid dispersions: a hypothesis-driven review, Eur. J. Lipid Sci. Technol. 122 (2020) 1900209. https://doi.org/10.1002/ejlt.201900209.

[79] V.A. Timoshnikov, L.A. Kichigina, O.Y. Selyutina, N.E. Polyakov, G.J. Kontoghiorghes, Antioxidant activity of deferasirox and its metal complexes in model systems of oxidative damage: comparison with deferiprone, Molecules. $26 \quad$ (2021) 5064. https://doi.org/10.3390/molecules26165064.

[80] J.F. Perez-Benito, Iron(III)-hydrogen peroxide reaction: kinetic evidence of a hydroxylmediated chain mechanism, J. Phys. Chem. A. 108 (2004) 4853-4858. https://doi.org/10.1021/jp0313391. 
[81] K. Barbusiński, Fenton reaction - controversy concerning the chemistry, Ecol Chem Eng. 16 (2009) 347-358.

[82] J. Björnerås, M. Nilsson, L. Mäler, Analysing DHPC/DMPC bicelles by diffusion NMR and multivariate decomposition, Biochim. Biophys. Acta. 1848 (2015) 2910-2917. https://doi.org/10.1016/j.bbamem.2015.09.002.

[83] M.A. Gonzálvez, A.G. Algarra, M.G. Basallote, P.V. Bernhardt, M.J. Fernández-Trujillo, M. Martínez, Proton-assisted air oxidation mechanisms of iron(II) bis-thiosemicarbazone complexes at physiological pH: a kinetico-mechanistic study, Dalton Trans. 48 (2019) 1657816587. https://doi.org/10.1039/C9DT03557E.

[84] M. Tóth, Z. Kukor, S. Valent, Chemical stabilization of tetrahydrobiopterin by L-ascorbic acid: contribution to placental endothelial nitric oxide synthase activity, Mol. Hum. Reprod. 8 (2002) 271-280. https://doi.org/10.1093/molehr/8.3.271.

[85] G. Silveira-Dorta, D.M. Monzón, F.P. Crisóstomo, T. Martín, V.S. Martín, R. Carrillo, Oxidation with air by ascorbate-driven quinone redox cycling, Chem. Commun. 51 (2015) 7027-7030. https://doi.org/10.1039/C5CC01519G.

[86] J. Verrax, R. Beck, N. Dejeans, C. Glorieux, B. Sid, R.C. Pedrosa, J. Benites, D. Vásquez, J.A. Valderrama, P.B. Calderon, Redox-active quinones and ascorbate: an innovative cancer therapy that exploits the vulnerability of cancer cells to oxidative stress, Anticancer Agents Med. Chem. 11 (2011) 213-221. https://doi.org/10.2174/187152011795255902.

[87] Y. Li, T. Zhu, J. Zhao, B. Xu, Interactive enhancements of ascorbic acid and iron in hydroxyl radical generation in quinone redox cycling, Environ. Sci. Technol. 46 (2012) 10302-10309. https://doi.org/10.1021/es301834r.

[88] B. Ye, L. Wang, Z. Zhang, Study on the electrochemical behaviour of the anti-cancer herbal drug emodin, Anal. Chem. Indian J. 2 (2006). https://www.tsijournals.com/abstract/study-onthe-electrochemical-behaviour-of-the-anticancer-herbal-drug-emodin-79.html (accessed December 7, 2021).

[89] L. Wang, Z. Zhang, B. Ye, Study on the electrochemical behaviour of the anti-cancer herbal drug emodin, Electrochimica Acta. $51 \quad$ (2006) 5961-5965. https://doi.org/10.1016/j.electacta.2006.03.082.

[90] S. Rahimipour, G. Gescheidt, I. Bilkis, M. Fridkin, L. Weiner, Towards the efficiency of pharmacologically active quinoid compounds: electron transfer and formation of reactive oxygen species, Appl. Magn. Reson. 37 (2010) 629-648. https://doi.org/10.1007/s00723-0090099-y. 
[91] A.R. da Cunha, E.L. Duarte, H. Stassen, M.T. Lamy, K. Coutinho, Experimental and theoretical studies of Emodin interacting with a lipid bilayer of DMPC, Biophys. Rev. 9 (2017) 729-745. https://doi.org/10.1007/s12551-017-0323-1.

[92] C. Stefani, P.J. Jansson, E. Gutierrez, P.V. Bernhardt, D.R. Richardson, D.S. Kalinowski, Alkyl substituted 2'-benzoylpyridine thiosemicarbazone chelators with potent and selective anti-neoplastic activity: novel ligands that limit methemoglobin formation, J. Med. Chem. 56 (2013) 357-370.

[93] C. Stefani, G. Punnia-Moorthy, D.B. Lovejoy, P.J. Jansson, D.S. Kalinowski, P.C. Sharpe, P.V. Bernhardt, D.R. Richardson, Halogenated 2'-benzoylpyridine thiosemicarbazone (XBpT) chelators with potent and selective anti-neoplastic activity: relationship to intracellular redox activity, J. Med. Chem. 54 (2011) 6936-6948. https://doi.org/10.1021/jm200924c.

[94] L. Zhang, C. Chang, S.S. Bacus, M.-C. Hung, Suppressed transformation and induced differentiation of HER-2/neu-overexpressing breast cancer cells by Emodin, Cancer Res. 55 (1995) 3890-3896.

[95] G. Srinivas, R.J. Anto, P. Srinivas, S. Vidhyalakshmi, V.P. Senan, D. Karunagaran, Emodin induces apoptosis of human cervical cancer cells through poly(ADP-ribose) polymerase cleavage and activation of caspase-9, Eur. J. Pharmacol. 473 (2003) 117-125. https://doi.org/10.1016/S0014-2999(03)01976-9.

[96] A.R. da Cunha, E.L. Duarte, M.T. Lamy, K. Coutinho, Protonation/deprotonation process of Emodin in aqueous solution and $\mathrm{pKa}$ determination: UV/Visible spectrophotometric titration and quantum/molecular mechanics calculations, Chem. Phys. 440 (2014) 69-79. https://doi.org/10.1016/j.chemphys.2014.06.009.

[97] M. Orsi, J.W. Essex, Permeability of drugs and hormones through a lipid bilayer: insights from dual-resolution molecular dynamics, Soft Matter. 6 (2010) 3797-3808. https://doi.org/10.1039/COSM00136H.

[98] M.B. Boggara, R. Krishnamoorti, Partitioning of nonsteroidal antiinflammatory drugs in lipid membranes: a molecular dynamics simulation study, Biophys. J. 98 (2010) 586-595. https://doi.org/10.1016/j.bpj.2009.10.046.

[99] B.G. Levine, J.E. Stone, A. Kohlmeyer, Fast analysis of molecular dynamics trajectories with graphics processing units—Radial distribution function histogramming, J. Comput. Phys. 230 (2011) 3556-3569. https://doi.org/10.1016/j.jcp.2011.01.048.

[100] S.M. Hadi, M.F. Ullah, U. Shamim, S.H. Bhatt, A.S. Azmi, Catalytic therapy of cancer by ascorbic acid involves redox cycling of exogenous/endogenous copper ions and generation of reactive oxygen species, Chemotherapy. $56 \quad$ (2010) 280-284. https://doi.org/10.1159/000319951. 
[101] N. Rozanova (Torshina), J.Z. Zhang, D.E. Heck, Catalytic therapy of cancer with porphyrins and ascorbate, Cancer Lett. 252 (2007) 216-224. https://doi.org/10.1016/j.canlet.2006.12.026.

[102] P. Zhang, P.J. Sadler, Redox-active metal complexes for anti-cancer therapy, Eur. J. Inorg. Chem. 2017 (2017) 1541-1548. https://doi.org/10.1002/ejic.201600908.

[103] P.J. Jansson, T. Yamagishi, A. Arvind, N. Seebacher, E. Gutierrez, A. Stacy, S. Maleki, D. Sharp, S. Sahni, D.R. Richardson, Di-2-pyridylketone 4,4-Dimethyl-3-thiosemicarbazone (Dp44mT) overcomes multidrug resistance by a novel mechanism involving the hijacking of lysosomal P-glycoprotein (Pgp), J. Biol. Chem. $290 \quad$ (2015) 9588-9603. https://doi.org/10.1074/jbc.M114.631283.

[104] K. Danielsen, D.W. Aksnes, G.W. Francis, NMR study of some anthraquinones from rhubarb, Magn. Reson. Chem. 30 (1992) 359-360. https://doi.org/10.1002/mrc.1260300414.

Table 1. Rate constants for the initiation reaction of LA peroxidation in micelles induced by the Dp44mT-Fe complex and the Emodin/Fe mixture relative to the control (i.e., Fe(II) added as $\left.\mathrm{FeSO}_{4}\right)$ in the presence and absence of ascorbate $(2.5 \mathrm{mM})$. These peroxidation studies were performed at $20^{\circ} \mathrm{C}$ using a suspension of LA micelles consisting of $3.5 \mathrm{mM} \mathrm{LA}, 0.5 \mathrm{M} \mathrm{H}_{2} \mathrm{O}_{2}, 0.1$ $\mathrm{mM} \mathrm{FeSO}_{4}(\mathrm{Fe}(\mathrm{II}))$, or instead of $\mathrm{FeSO}_{4}, 0.1 \mathrm{mM}$ of the Dp44mT-Fe complex or Emodin/iron mixture (i.e., $[\mathrm{Dp} 44 \mathrm{mT}$ or Emodin $]=0.2 \mathrm{mM}$ and $[\mathrm{Fe}]=0.1 \mathrm{mM}$; see Materials and Methods) in PBS (pH 7.4).

\begin{tabular}{|l|l|l|l|l|}
\hline & control (Fe(II)) & $\mathrm{Fe}(\mathrm{III})-\mathrm{Dp} 44 \mathrm{mT}$ & $\mathrm{Fe}(\mathrm{II})-\mathrm{Dp} 44 \mathrm{mT}$ & $\mathrm{Fe}(\mathrm{II}) / \mathrm{Emodin}$ \\
\hline$(-)$ ascorbate & $3.60 \pm 0.80 \times 10^{-4} \mathrm{~s}^{-1}$ & $0.33 \pm 0.03 \times 10^{-4} \mathrm{~s}^{-1}$ & $2.50 \pm 0.30 \times 10^{-4} \mathrm{~s}^{-1}$ & $5.50 \pm 0.30 \times 10^{-4} \mathrm{~s}^{-1}$ \\
\hline$(+)$ ascorbate & $27.00 \pm 0.40 \times 10^{-4} \mathrm{~s}^{-1}$ & $1.30 \pm 0.20 \times 10^{-4} \mathrm{~s}^{-1}$ & $5.60 \pm 0.40 \times 10^{-4} \mathrm{~s}^{-1}$ & $11.90 \pm 0.40 \times 10^{-4} \mathrm{~s}^{-1}$ \\
\hline
\end{tabular}


Table 2. Rate constants for the initiation reaction of lipid peroxidation at $20{ }^{\circ} \mathrm{C}$ for DLPC/DHPC bicelles consisting of $4 \mathrm{mM}$ DLPC, $8 \mathrm{mM}$ DHPC, $0.5 \mathrm{M} \mathrm{H}_{2} \mathrm{O}_{2}$, and $0.1 \mathrm{mM} \mathrm{FeSO}_{4}$ (control Fe(II)), or instead of $\mathrm{FeSO}_{4},[\mathrm{Dp} 44 \mathrm{mT}$ or Emodin $]=0.2 \mathrm{mM}$ and $[\mathrm{Fe}]=0.1 \mathrm{mM}$ (see Materials and Methods) in PBS (pH 7.4). Results are mean \pm SD (3 experiments).

\begin{tabular}{|l|c|c|c|c|}
\hline & control (Fe(II)) & Fe(III)-Dp44mT & Fe(II)-Dp44mT & Fe(II)/Emodin \\
\hline (-) ascorbate & $4.10 \pm 1.00 \times 10^{-4} \mathrm{~s}^{-1}$ & $0.02 \pm 0.01 \times 10^{-4} \mathrm{~s}^{-1}$ & $0.30 \pm 0.05 \times 10^{-4} \mathrm{~s}^{-1}$ & $5.20 \pm 0.70 \times 10^{-4} \mathrm{~s}^{-1}$ \\
\hline$(+)$ ascorbate & $26.00 \pm 6.00 \times 10^{-4} \mathrm{~s}^{-1}$ & $11.00 \pm 3.00 \times 10^{-4} \mathrm{~s}^{-1}$ & $13.00 \pm 2.00 \times 10^{-4} \mathrm{~s}^{-1}$ & $5.30 \pm 0.10 \times 10^{-4} \mathrm{~s}^{-1}$ \\
\hline
\end{tabular}

\section{Figure Legends}

Figure 1. Line drawings of the chemical structures of: (A) 6-methyl-1,3,8-trihydroxyanthraquinone (Emodin); (B) di-2-pyridylketone 4,4-dimethyl-3-thiosemicarbazone (Dp44mT); (C) the potential 2:1 Emodin-Fe complex; and (D) the well characterized 2:1 Dp44mT-Fe complex [59].

Figure 2. Line drawings of the chemical structures of: (A) linoleic acid (LA; bis-allylic proton shown by asterisk); (B) 1,2-dilinoleoyl-sn-glycero-3-phosphocholine (DLPC; bis-allylic protons shown by asterisk); (C) 1,2-diheptanoyl-sn-glycero-3-phosphocholine (DHPC); and (D) 1,2dioleoyl-sn-glycero-3-phosphocholine (DOPC).

Figure 3. (A) ${ }^{1} \mathrm{H}$ NMR spectra of the initial LA solution $(3.5 \mathrm{mM})$ and also LA $(3.5 \mathrm{mM})$ incubated with $\mathrm{H}_{2} \mathrm{O}_{2}(0.5 \mathrm{M})$ and $\mathrm{FeSO}_{4}(0.1 \mathrm{mM})$ after a 2, 4, and $24 \mathrm{~h}$ incubation at $20{ }^{\circ} \mathrm{C}(\mathrm{pH} 7.4)$. (B) ${ }^{1} \mathrm{H}$ NMR spectra of the initial DLPC/DHPC mixture and also DLPC/DHPC incubated with $\mathrm{H}_{2} \mathrm{O}_{2}(0.5$ M) and $\mathrm{FeSO}_{4}(0.1 \mathrm{mM})$ after a 2- and 24-h incubation at $20{ }^{\circ} \mathrm{C}(\mathrm{pH} 7.4)$. Results are a typical experiment from 3 performed. 
Figure 4. Kinetics of the initiation reaction of LA peroxidation in the absence and presence of Fe and Dp44mT or Emodin (see Materials and Methods for details), either: (A) without ascorbate, or (B) with $2.5 \mathrm{mM}$ ascorbate at $20^{\circ} \mathrm{C}$. Peroxidation studies were performed using $3.5 \mathrm{mM} \mathrm{LA}, 0.5 \mathrm{M}$ $\mathrm{H}_{2} \mathrm{O}_{2}, 0.1 \mathrm{mM} \mathrm{FeSO} 4$ (pH 7.4), or $0.1 \mathrm{mM}$ of the Fe-Dp44mT complex or Fe/Emodin mixtures (i.e., $[\mathrm{Dp} 44 \mathrm{mT}$ or Emodin $]=0.2 \mathrm{mM}$ and $[\mathrm{Fe}]=0.1 \mathrm{mM})$. Graphs are based on the decay of the integral intensity of the protons at $2.7 \mathrm{ppm}$. Results are a typical experiment from 3 performed.

Figure 5. Kinetics of the initiation reaction of the lipid peroxidation of DLPC/DHPC bicelles in the absence and presence of Fe and Dp44mT or Emodin (see Materials and Methods for details), either: (A) without ascorbate, or (B) with $2.5 \mathrm{mM}$ ascorbate at $20{ }^{\circ} \mathrm{C}$. Peroxidation studies were performed using $4 \mathrm{mM}$ DLPC, $8 \mathrm{mM}$ DHPC, $0.5 \mathrm{M} \mathrm{H}_{2} \mathrm{O}_{2}$, and $0.1 \mathrm{mM} \mathrm{FeSO}_{4}$ (control Fe(II)), or alternatively, $[\mathrm{Dp} 44 \mathrm{mT}$ or Emodin $]=0.2 \mathrm{mM}$ and $[\mathrm{Fe}]=0.1 \mathrm{mM}($ see Materials and Methods $)$ in PBS (pH 7.4). Graphs are based on the decay of the integral intensity of the protons at $2.7 \mathrm{ppm}$. Results are a typical experiment from 3 performed.

Figure 6. UV-Vis absorption spectra of solutions at $20{ }^{\circ} \mathrm{C}$ containing of $\mathrm{FeSO}_{4}(0.05 \mathrm{mM})$, Dp44mT $(0.1 \mathrm{mM})$, and ascorbate in the concentration range $(0-0.8 \mathrm{mM})$ in PBS (pH 7.4). Results are a typical experiment from 3 performed.

Figure 7. UV-Vis absorption spectra of a solution at $20^{\circ} \mathrm{C}$ containing: (A) $0.1 \mathrm{mM}$ of Emodin and $0.1 \mathrm{mM}$ of ascorbate in $10 \%$ ethanol solution, $\mathrm{pH}$ 7.4. (B) $0.1 \mathrm{mM}$ Emodine, $0.05 \mathrm{mM} \mathrm{Fe}(\mathrm{II}), 0.1$ $\mathrm{mM}$ ascorbate, $10 \%$ ethanol solution, $\mathrm{pH}$ 7.4. Spectra were recorded in the interval of $0-2 \mathrm{~h}$. Results are a typical experiment from 3 performed. 
Figure 8. EPR spectra at $20{ }^{\circ} \mathrm{C}$ of either: Emodin $(10 \mathrm{mM})$ and ascorbate $(10 \mathrm{mM})$; ascorbate $(10$ $\mathrm{mM})$ alone; or Emodin $(10 \mathrm{mM})$, ascorbate $(10 \mathrm{mM})$, and $\mathrm{H}_{2} \mathrm{O}_{2}(10 \mathrm{mM})$ in a DMSO: water mixture (10\% v/v of DMSO; pH 9). Results are a typical experiment from 3 performed.

Figure 9. (A) Fragments of ${ }^{1} \mathrm{H}$ NMR spectra of Emodin in DLPC bicelles relative to LA micelles. Assignments were taken from [104]. (B) Fragments of ${ }^{1} \mathrm{H}$ NMR spectra of Dp44mT in DLPC bicelles relative to LA micelles. Results are a typical experiment from 3 performed.

Figure 10. Positions of (A) Dp44mT outside the lipid bilayer; (B) Dp44mT inside the lipid bilayer; (C) Emodin on the surface of DOPC membrane; and (D) Emodin inside the DOPC membrane. Simulations were performed with the neutral agents at $\mathrm{pH} 7.4$ (physiologically relevant conditions). Taken from molecular dynamics simulations.

Figure 11. (A) Radial distribution function of the sulfur atom of Dp44mT and the nitrogen atom of the DOPC phospholipids. (B) The minimum distance between the Dp44mT sulfur atom and the DOPC nitrogen atom as a function of time. Simulations were performed with the neutral agents at pH 7.4 (physiologically relevant conditions). Taken from molecular dynamics simulations.

Figure 12. Radial distribution function of the oxygen-atoms of Emodin and the phosphate group of DOPC. Simulations were performed with the neutral agents at $\mathrm{pH} 7.4$ (physiologically relevant conditions). Taken from molecular dynamics simulations.

Figure 13 Combination of ascorbate with (A) Dp44mT or (B) Emodin increases their antiproliferative activity against SK-Mel-28 melanoma cells relative to these agents alone or ascorbate alone (C). Cells were incubated for $72 \mathrm{~h} / 37^{\circ} \mathrm{C}$ with Dp44mT $(0-25 \mu \mathrm{M})$ or Emodin $(0-100 \mu \mathrm{M})$ 
alone or in the presence of ascorbate $(50 \mu \mathrm{M}$ or $1 \mathrm{mM})$. ${ }^{*} p<0.05, * * p<0.01, * * * p<0.001$ relative to Dp44mT alone. Results are mean $\pm \mathrm{SD}$ (3 experiments).

Figure 14 Schematic demonstrating that ascorbate drives redox cycling of the Fe-Dp44mT complex or Emodin/Fe mixture leading to ROS generation and lipid peroxidation. UV-Vis spectrophotometry demonstrated that ascorbate reduces Fe(III)-Dp44mT to Fe(II)-Dp44mT, leading to ROS generation and lipid peroxidation. The use of EPR spectroscopy indicated ascorbyl radical anion $\left(\mathrm{Asc}^{-}\right)$formation after mixing ascorbate and Emodin, with the EPR signal intensity being enhanced by $\mathrm{H}_{2} \mathrm{O}_{2}$. These data suggested formation of the Emodin semiquinone radical in Emodin/Fe mixtures could play a role in this compounds ability to induce lipid peroxidation via ascorbate-driven redox cycling. 


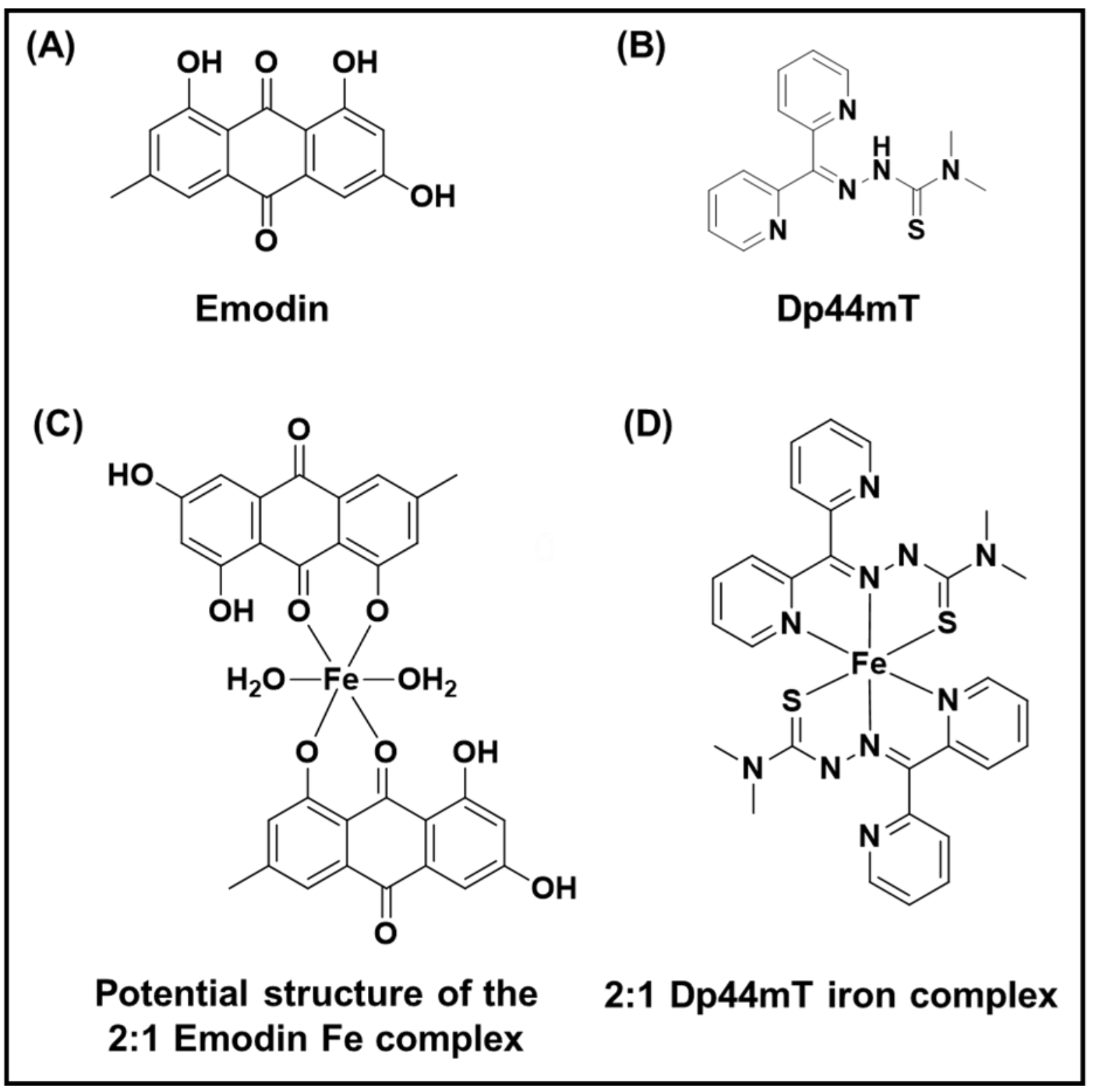

Figure 1 


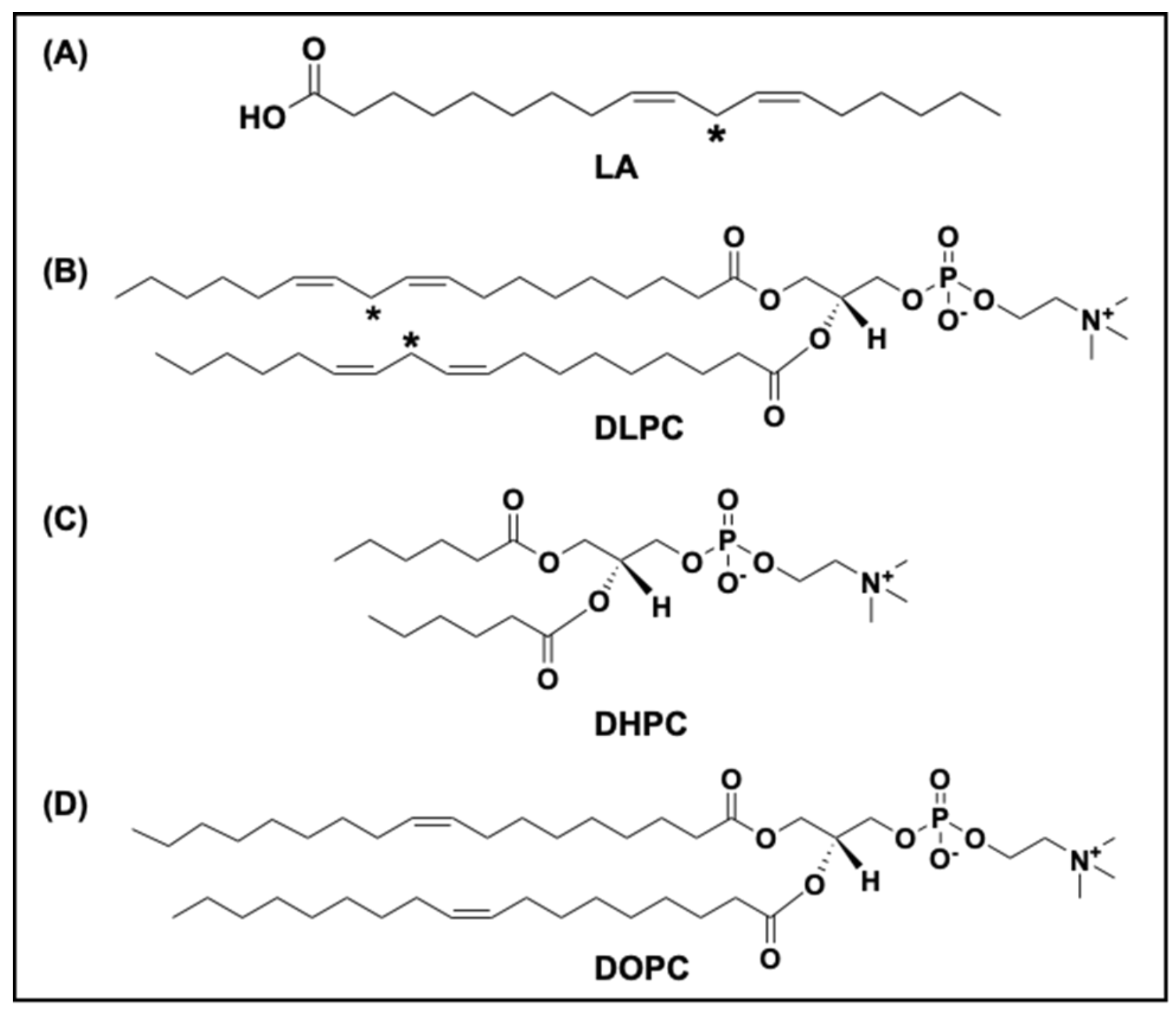

Figure 2 


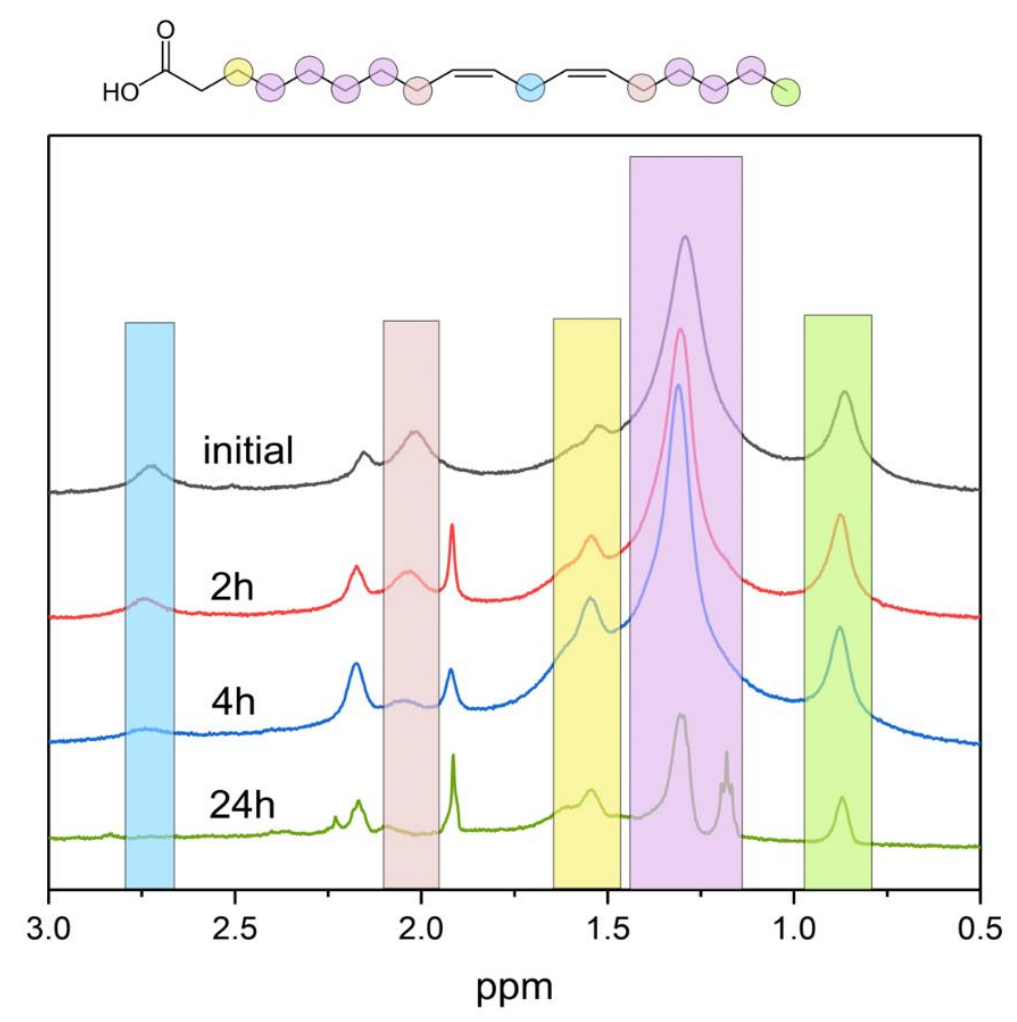

(B)

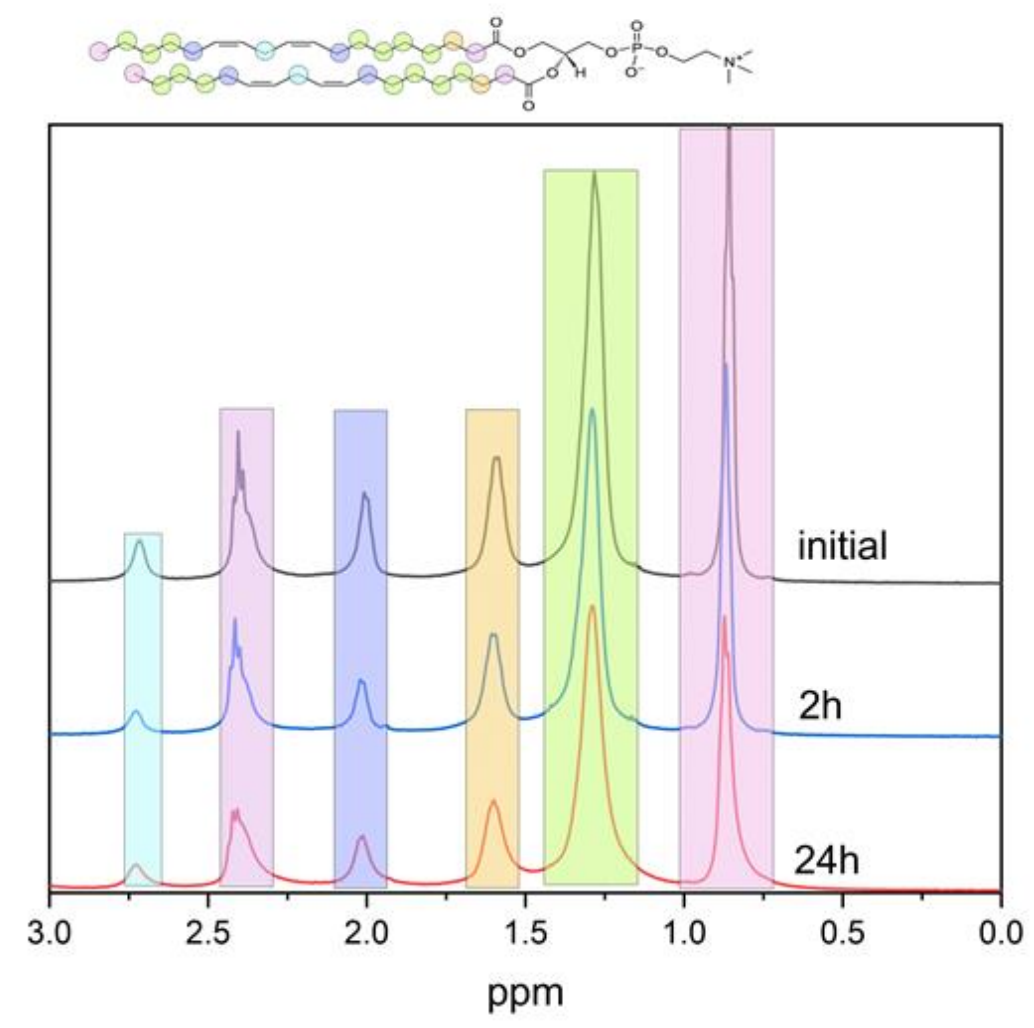

Figure 3 
(A)

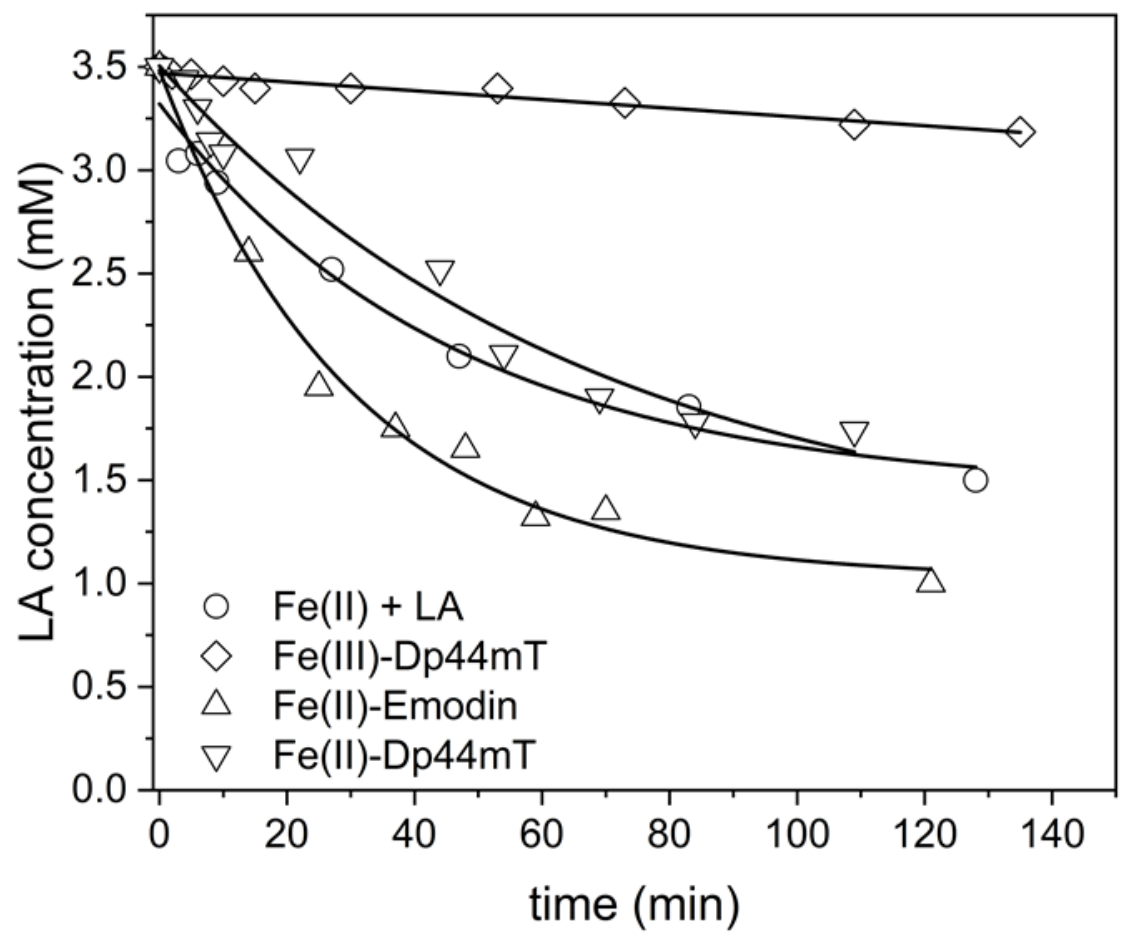

(B)

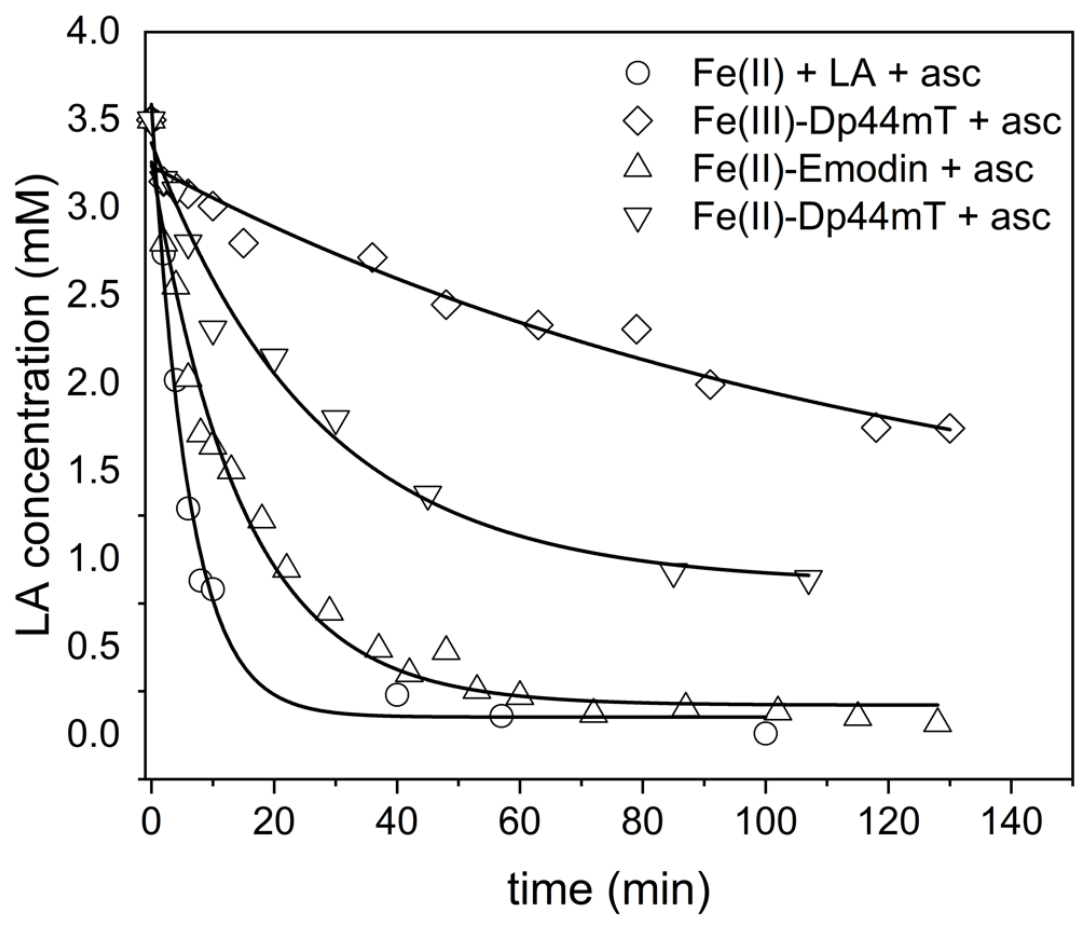

Figure 4 


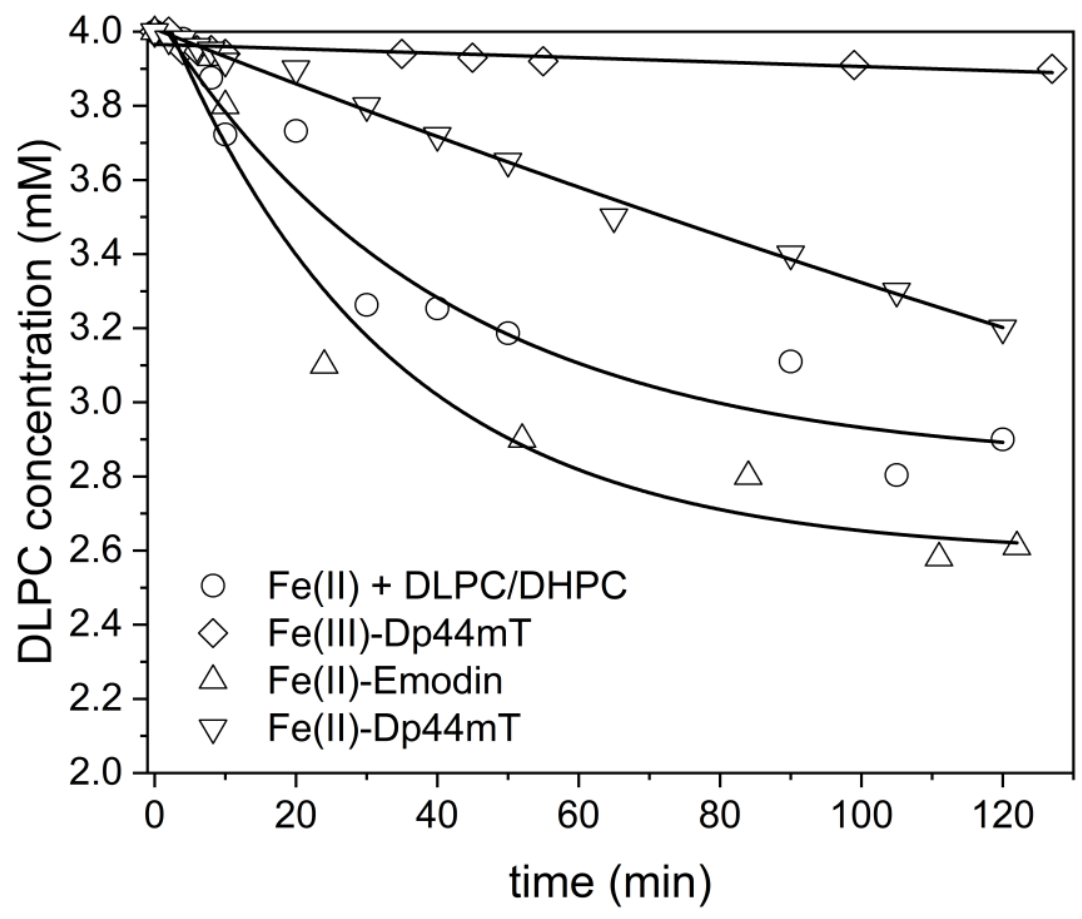

(B)

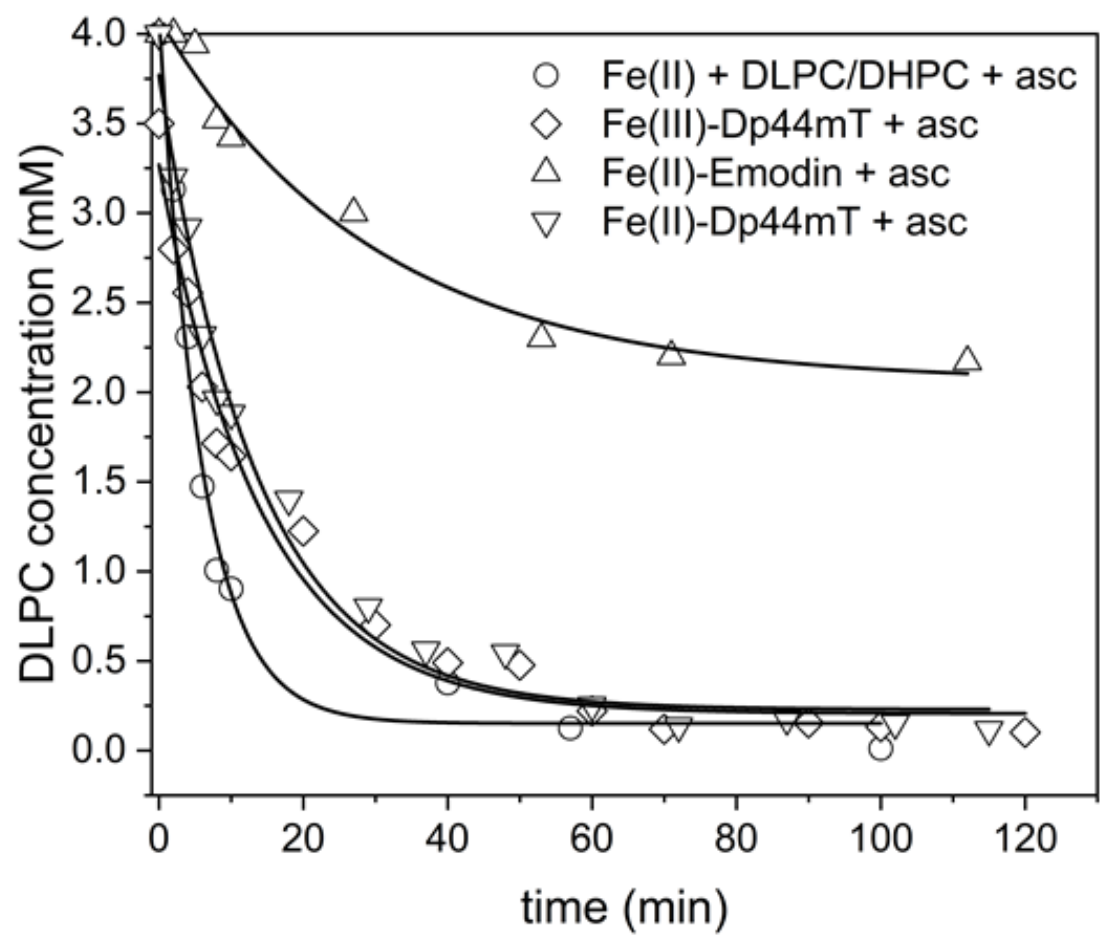

Figure 5 


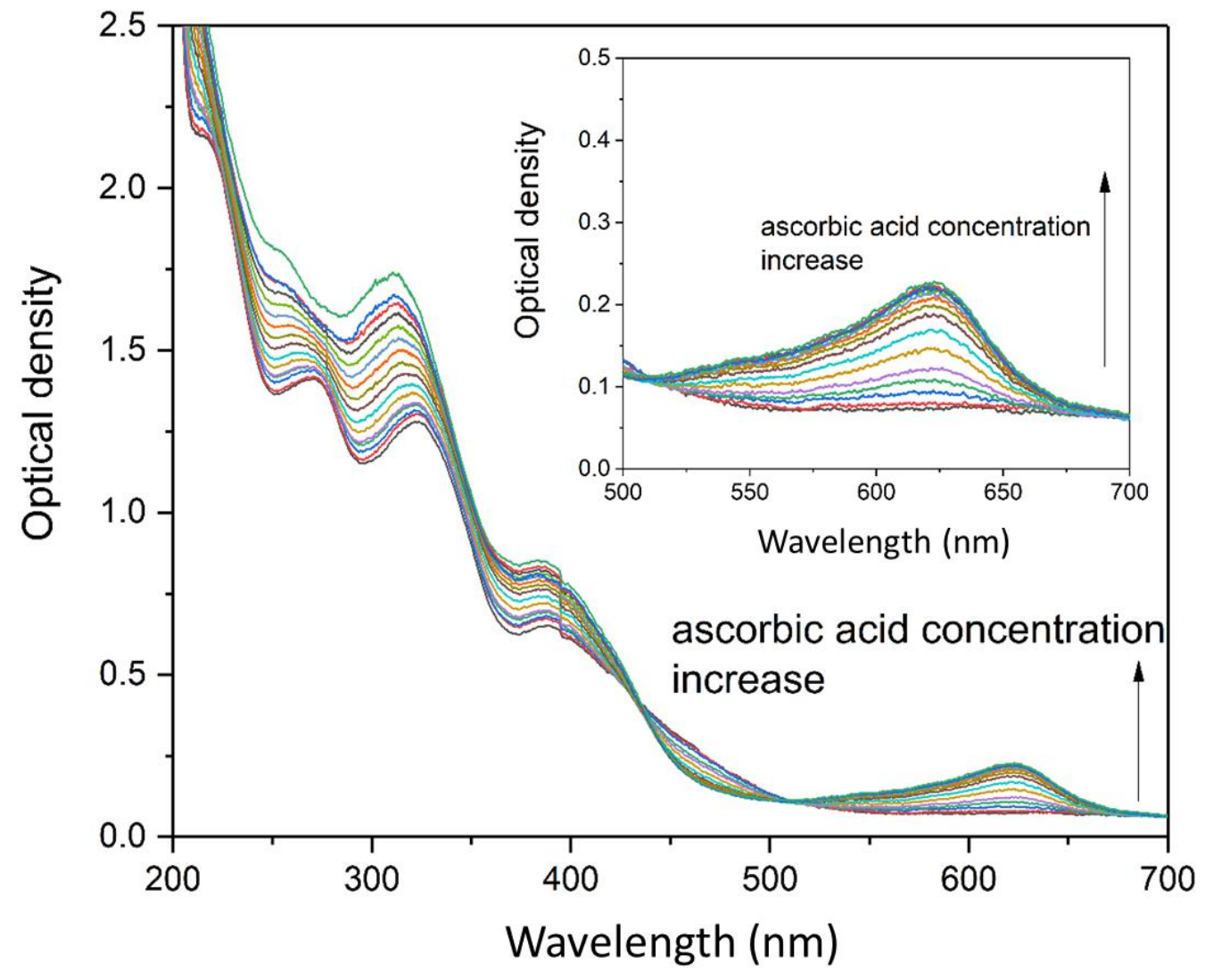

Figure 6 
(A)

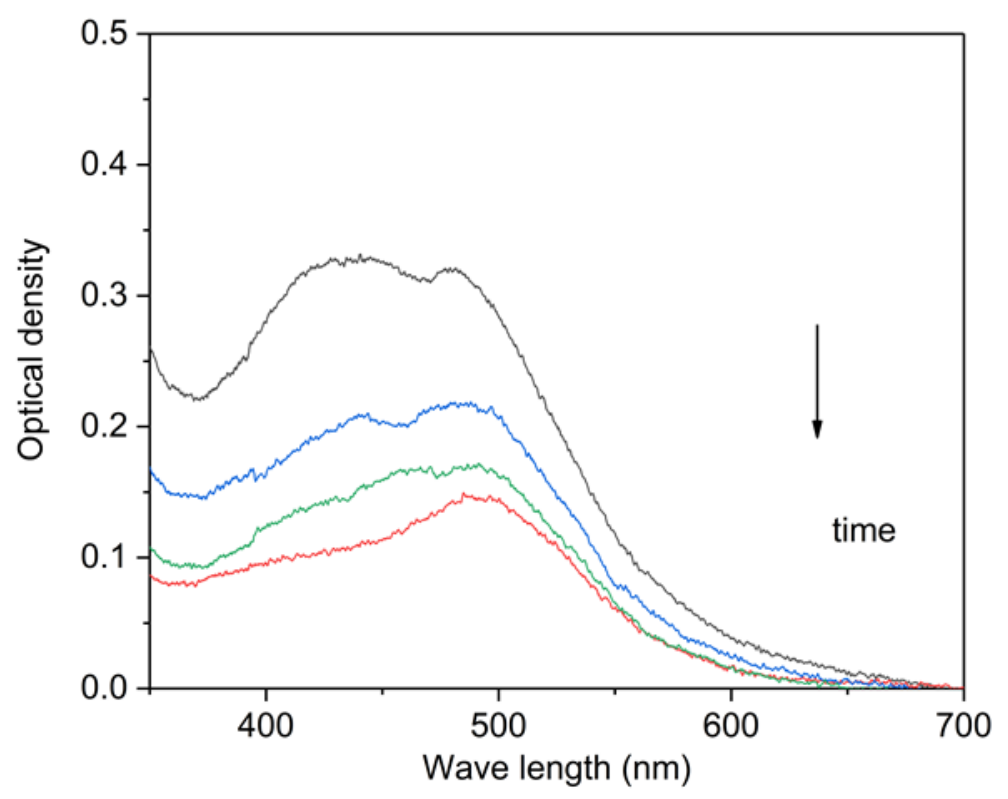

(B)

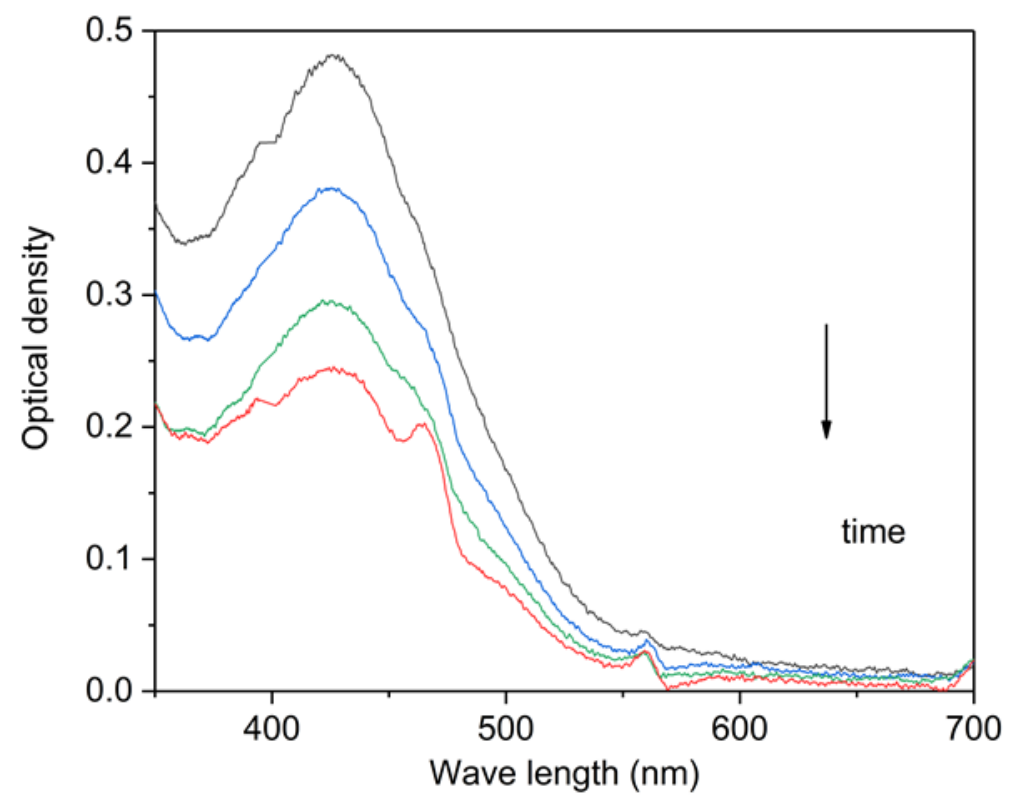

Figure 7 


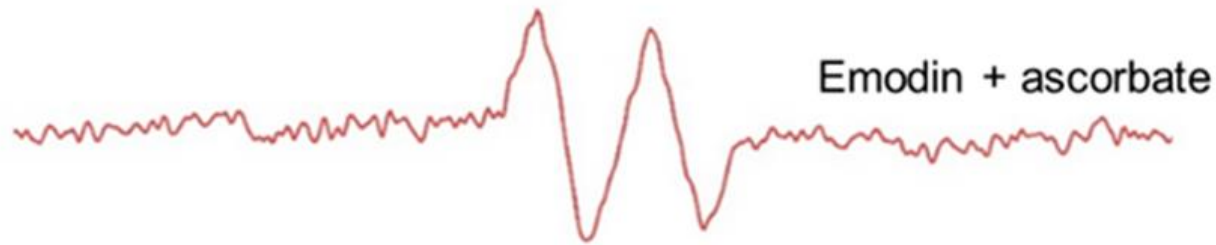

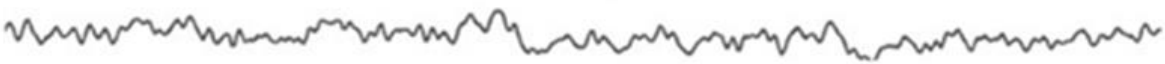

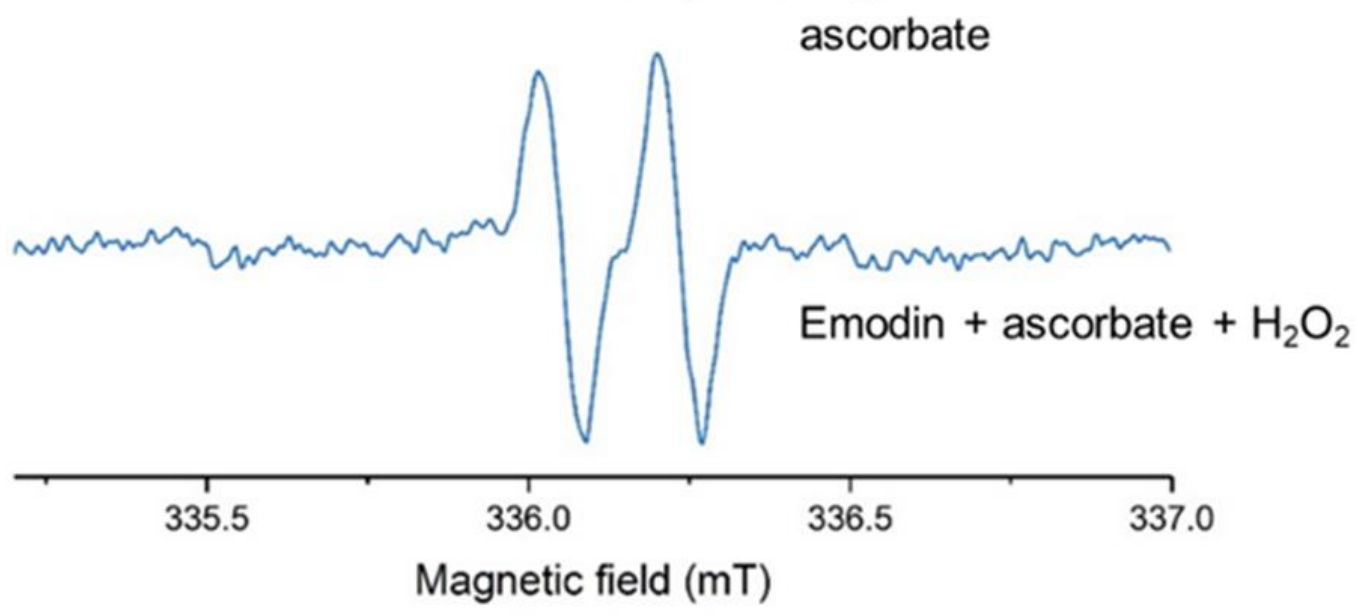

Figure 8 
(A)

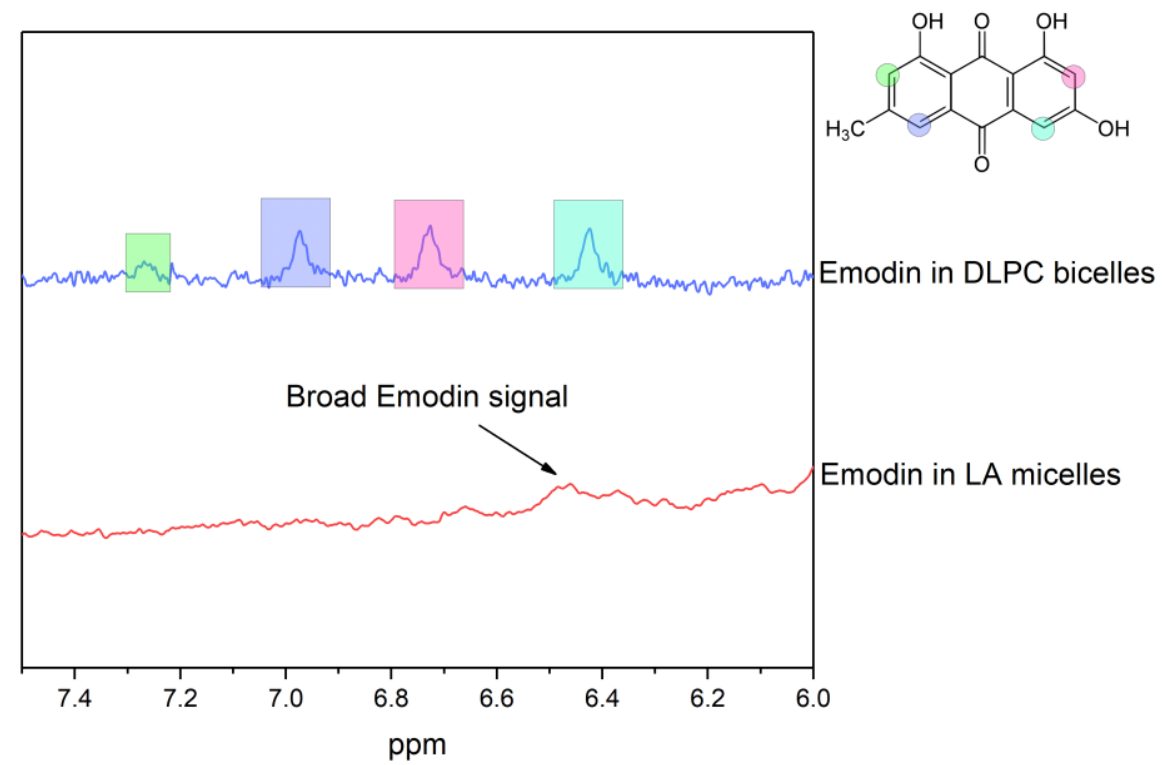

(B)

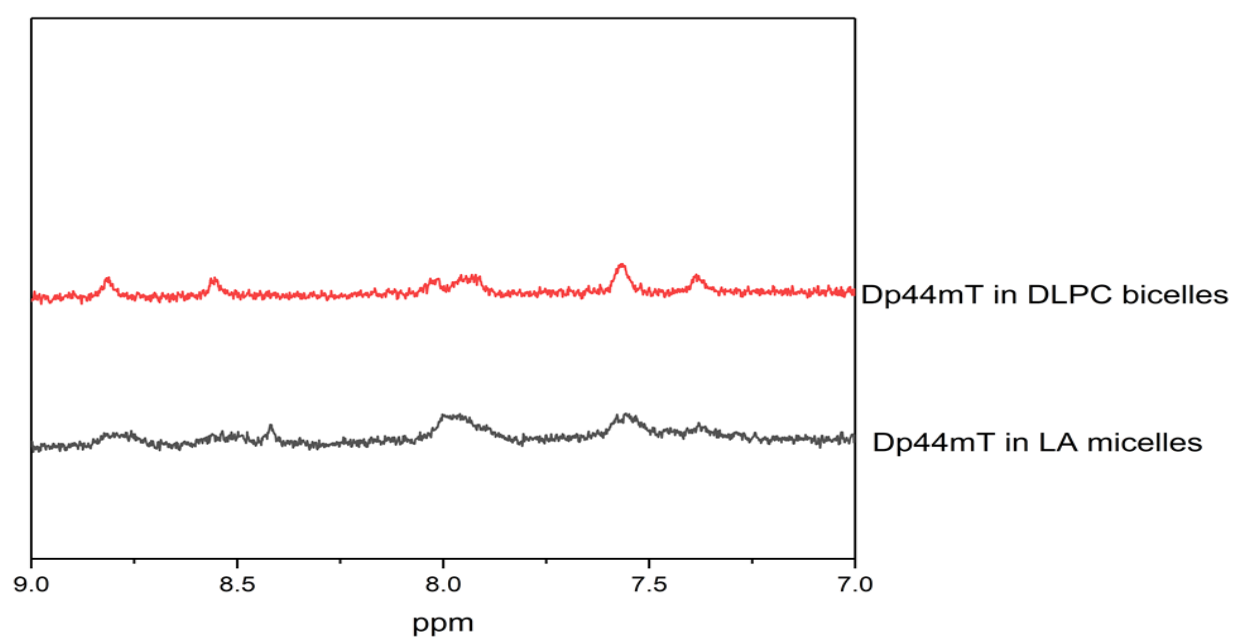

Figure 9 


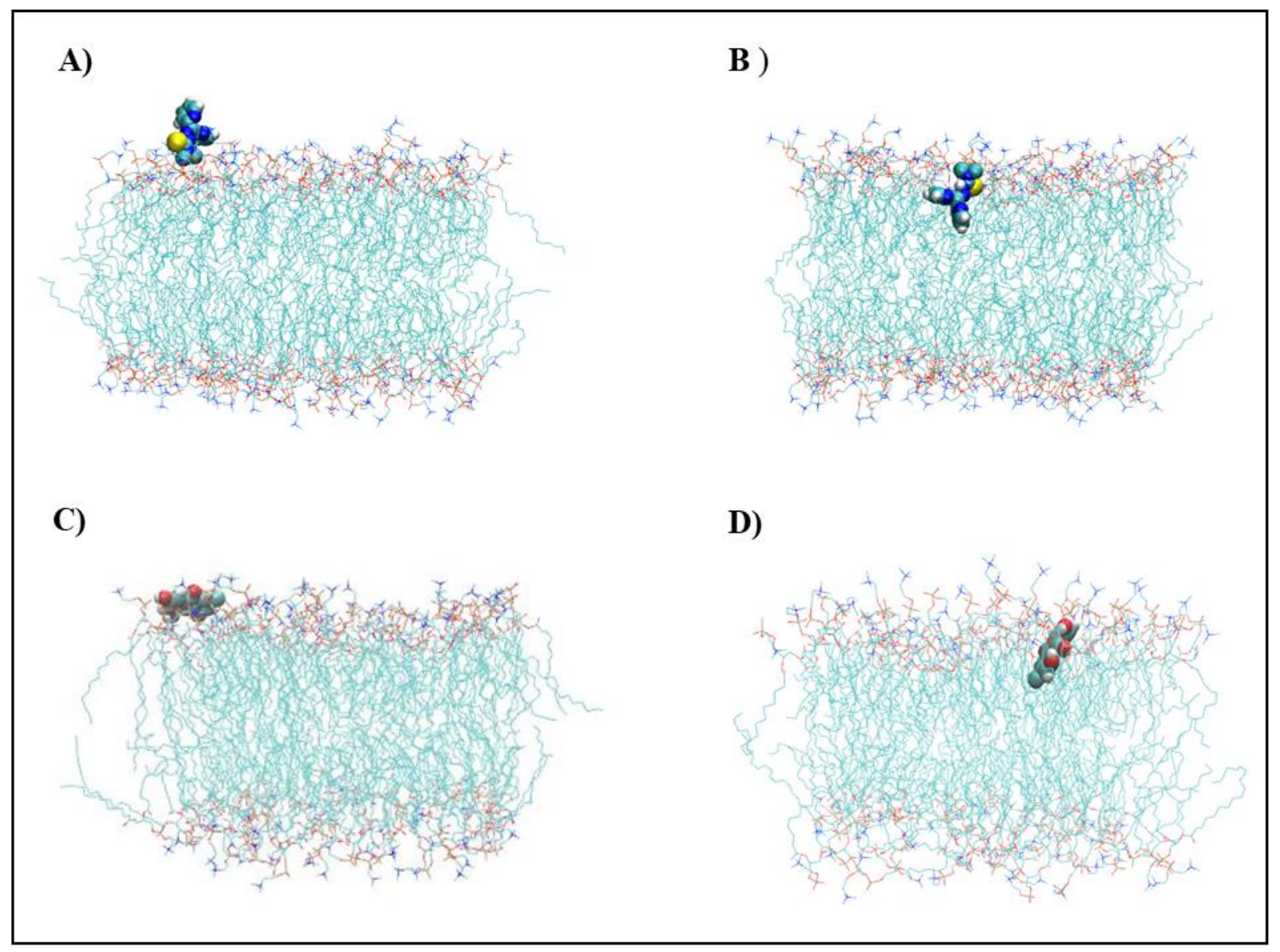

Figure 10 
(A)

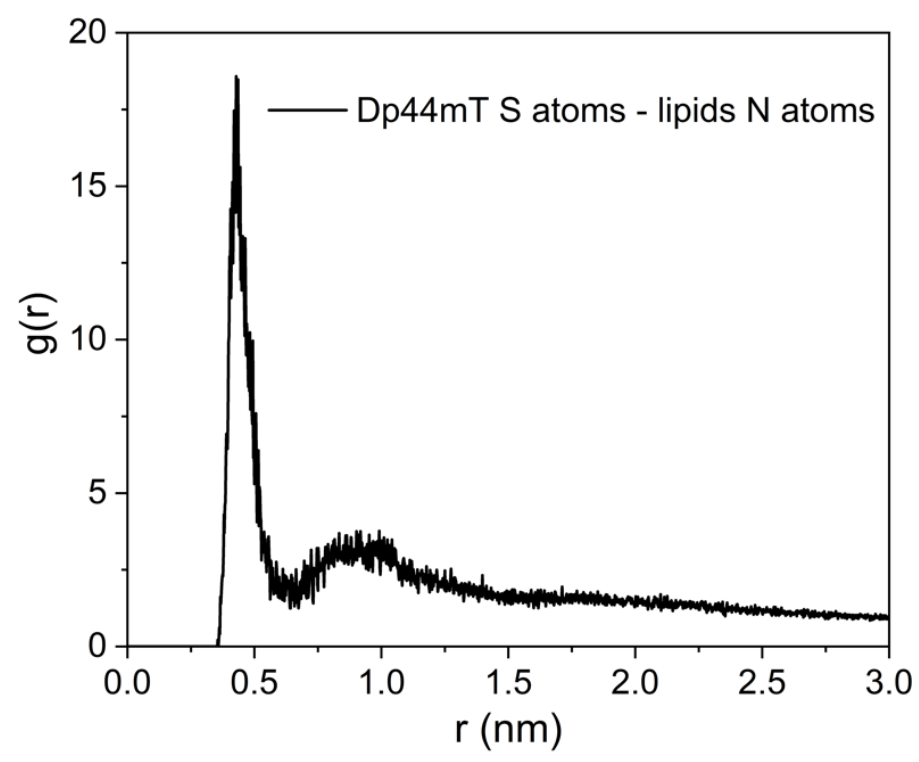

(B)

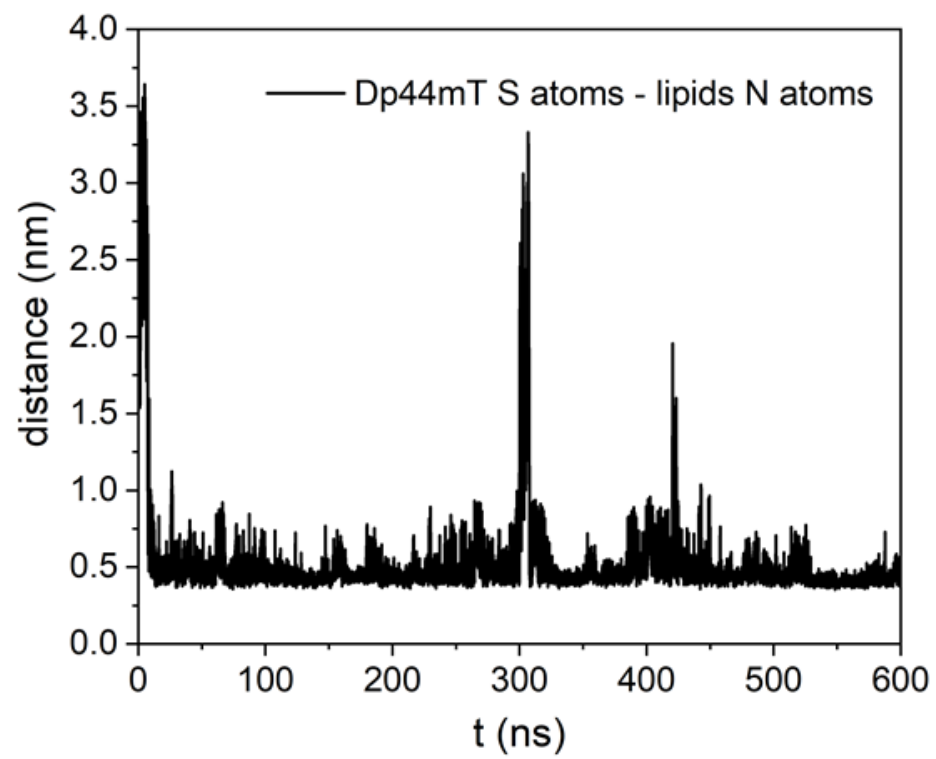

Figure 11 


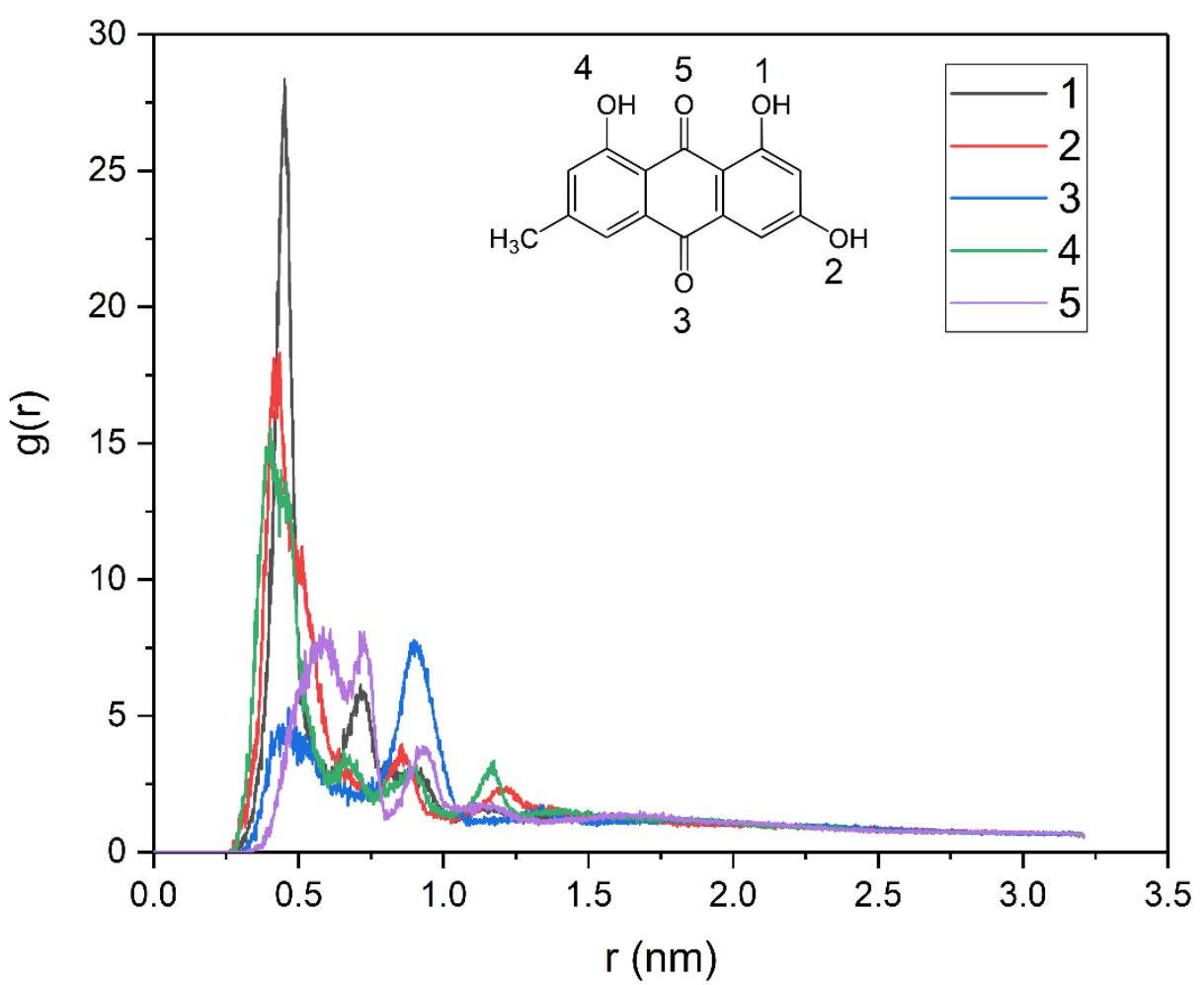

Figure 12 
(A)

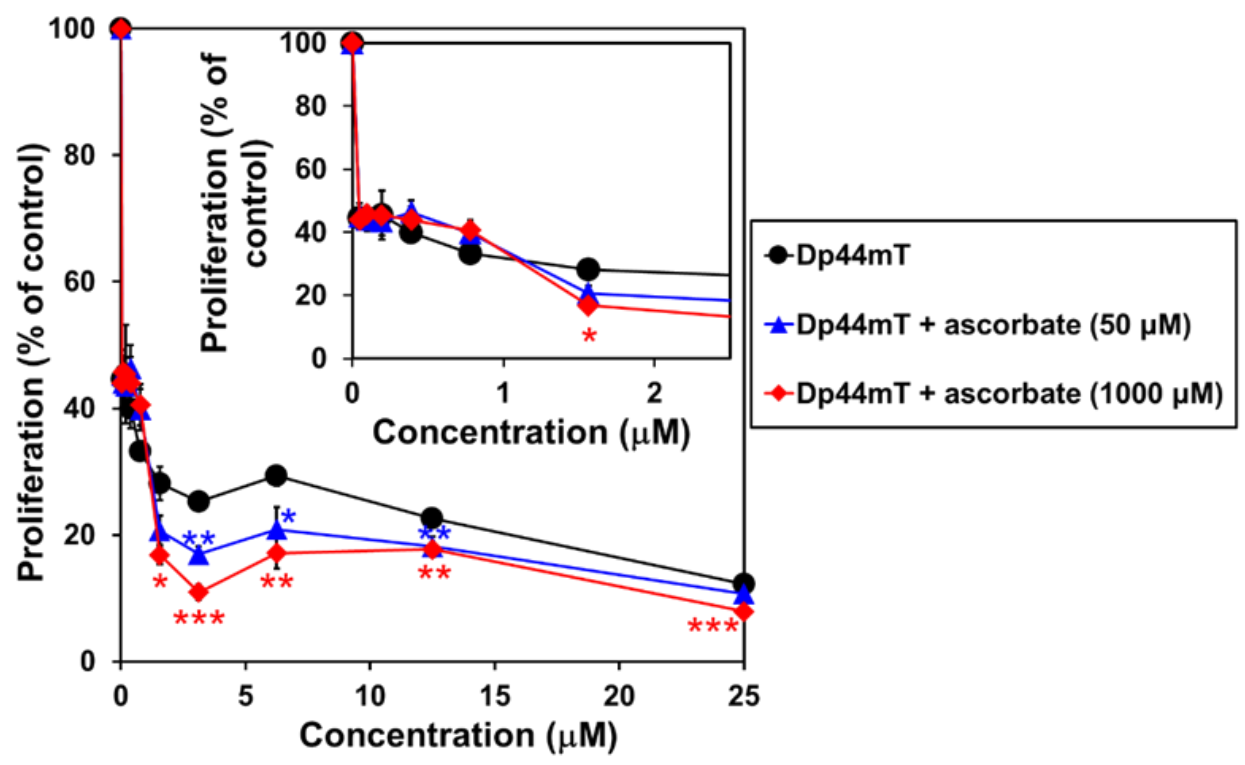

(B)

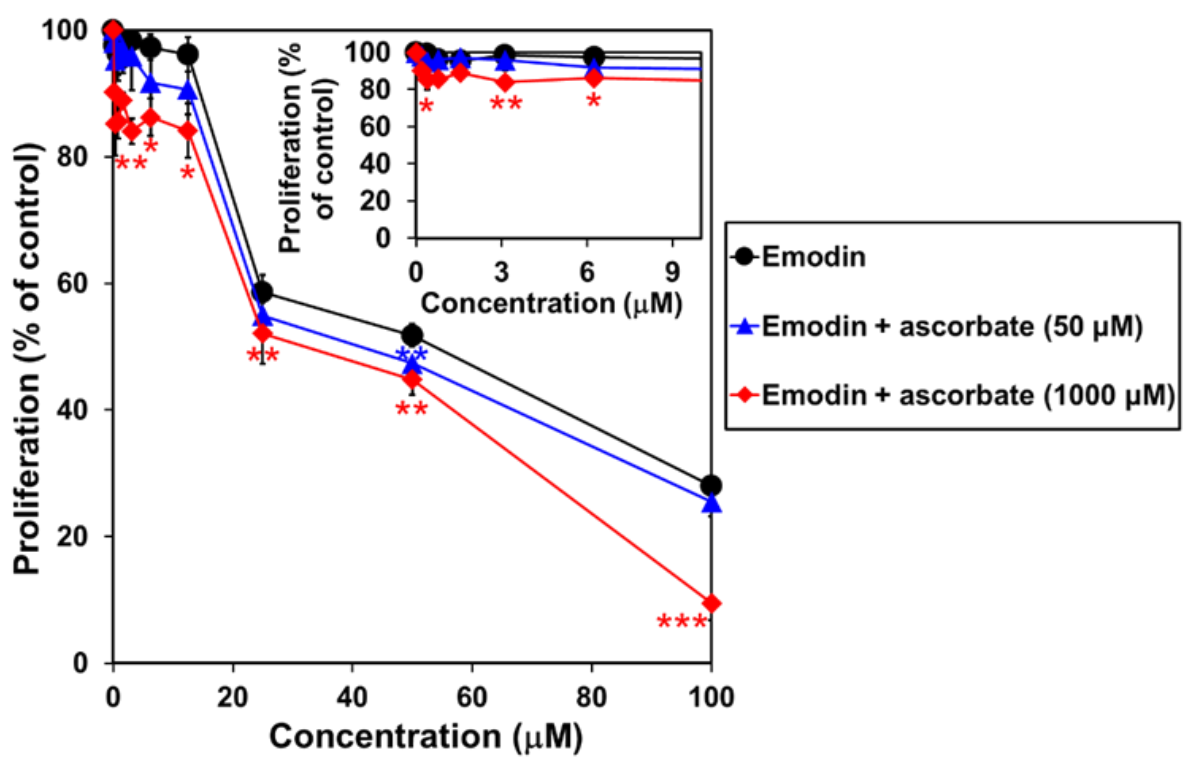

(C)

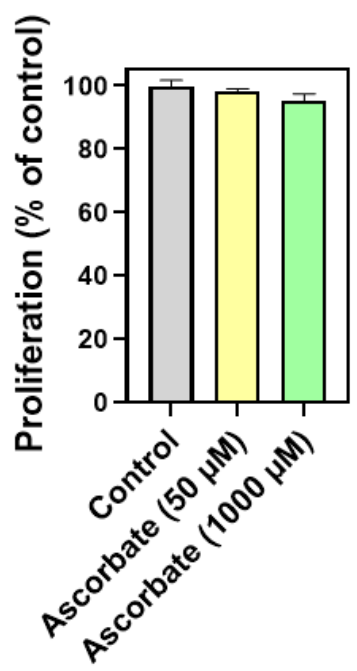




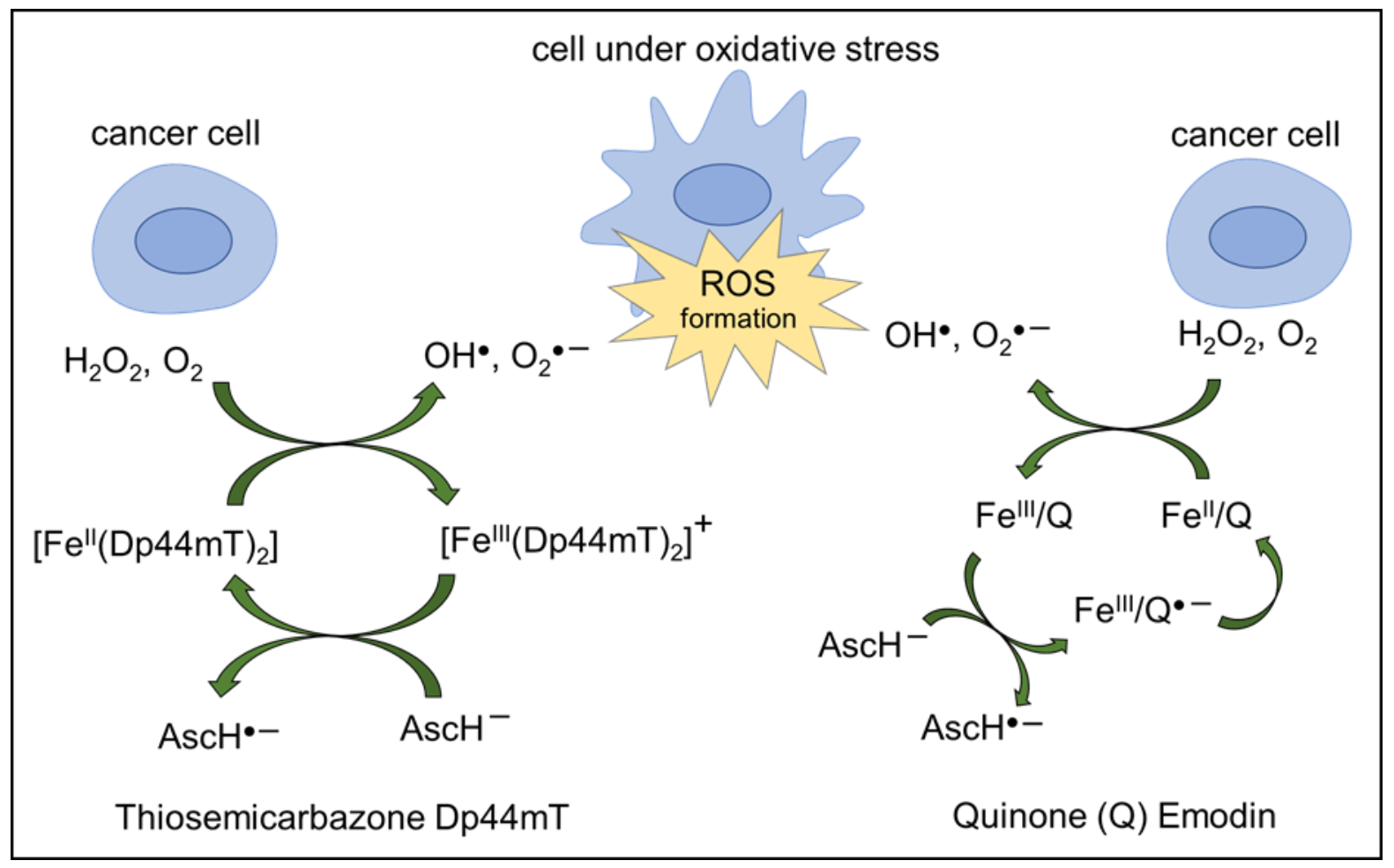

Figure 14 


\section{Credit Author Statement}

O.Y. Selyutina: conceptualization, funding, planning of experiments, supervision, writing, reviewing and editing; P.A. Kononova: planning and performance of experiments; E.A. Shelepova: Planning and performance of experiments; M. Gholam Azad: preparation of figures, editing, planning and performance of experiments; R. Afroz: data analysis, writing, editing; M. Dharmasivam: performance of experiments, preparation of figures, writing and editing; P.V. Bernhardt: preparation of figures, performance of experiments, writing, editing: N.E. Polyakov: conceptualization, funding, planning of experiments, supervision, writing, reviewing and editing; D.R. Richardson: conceptualization, funding, planning of experiments, supervision, writing, reviewing and editing. 


\section{Graphical Abstract}

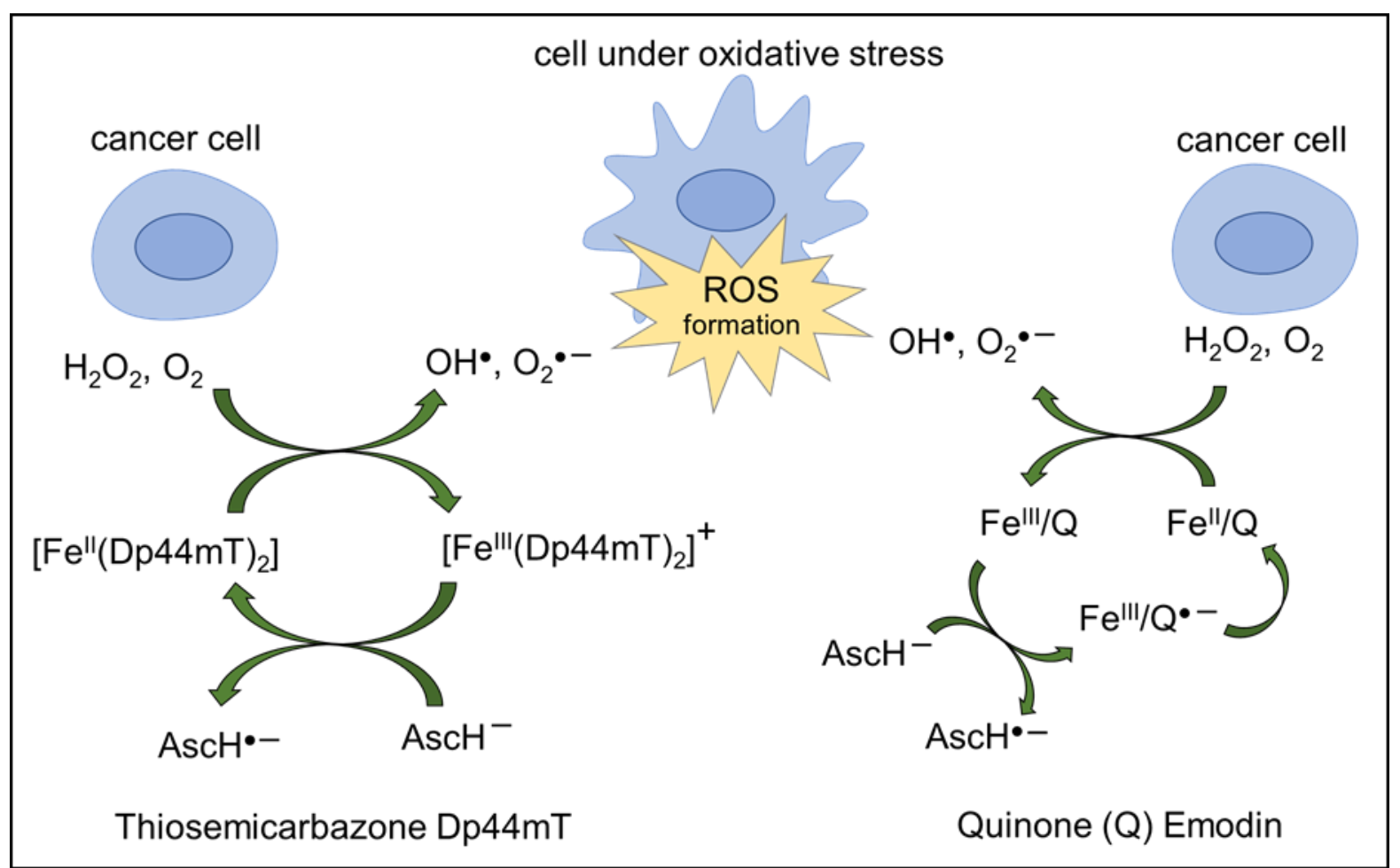

\section{Highlights}

- Iron(III)-Dp44mT complexes suppress lipid peroxidation.

- Ascorbate reduces iron(III)-Dp44mT to the redox-active iron(II)-Dp44mT complex.

- Iron(II)-Dp44mT complexes enhance lipid peroxidation.

- Ascorbate drives redox cycling of iron in the presence of Dp44mT and Emodin.

- Ascorbate enhances the in vitro anti-proliferative efficacy of Dp44mT and Emodin 